\title{
Genome-wide association study of yield and related traits in common wheat under salt-stress conditions
}

\author{
Pan Hu, Qi Zheng ${ }^{*}$, Qiaoling Luo, Wan Teng, Hongwei Li, Bin Li and Zhensheng Li
}

\begin{abstract}
Background: Soil salinization is a major threat to wheat production. It is essential to understand the genetic basis of salt tolerance for breeding and selecting new salt-tolerant cultivars that have the potential to increase wheat yield.

Result: In this study, a panel of 191 wheat accessions was subjected to genome wide association study (GWAS) to identify SNP markers linked with adult-stage characters. The population was genotyped by Wheat660K SNP array and eight phenotype traits were investigated under low and high salinity environments for three consecutive years. A total of 389 SNPs representing 11 QTLs were significantly associated with plant height, spike number, spike length, grain number, thousand kernels weight, yield and biological mass under different salt treatments, with the phenotypic explanation rate $\left(R^{2}\right)$ ranging from 9.14 to $50.45 \%$. Of these, repetitive and pleiotropic loci on chromosomes 4A, 5A, 5B and 7A were significantly linked to yield and yield related traits such as thousand kernels weight, spike number, spike length, grain number and so on under low salinity conditions. Spike length-related loci were mainly located on chromosomes 1B, 3B, 5B and 7A under different salt treatments. Two loci on chromosome $4 \mathrm{D}$ and $5 \mathrm{~A}$ were related with plant height in low and high salinity environment, respectively. Three salt-tolerant related loci were confirmed to be important in two bi-parental populations. Distribution of favorable haplotypes indicated that superior haplotypes of pleiotropic loci on group-5 chromosomes were strongly selected and had potential for increasing wheat salt tolerance. A total of 14 KASP markers were developed for nine loci associating with yield and related traits to improve the selection efficiency of wheat salt-tolerance breeding.

Conclusion: Utilizing a Wheat660K SNPs chip, QTLs for yield and its related traits were detected under salt treatment in a natural wheat population. Important salt-tolerant related loci were validated in RIL and DH populations. This study provided reliable molecular markers that could be crucial for marker-assisted selection in wheat salt tolerance breeding programs.
\end{abstract}

Keywords: Common wheat, Favorable allele, GWAS, Salt stress, Wheat660K SNP chip, Yield-related traits

\section{Background}

The arable land affected by salinity worldwide is greater than 800 million ha, which is analogous to $\sim 6 \%$ of the global land area [1-3]. Moreover, the proportion of salt-

\footnotetext{
* Correspondence: qzheng@genetics.ac.cn

State Key Laboratory of Plant Cell and Chromosome Engineering, Institute of Genetics and Developmental Biology, The Innovative Academy of Seed Design, Chinese Academy of Sciences, Beijing 100101, China
}

affected soil is increasing annually owing to irrigation, which could lead to salt accumulation in agricultural soils $[1,4]$. Therefore, salinization has become a major limitation of grain yield [2]. Common wheat (Triticum aestivum L.), an important cereal crop, provides calorific energy for $\sim 20 \%$ of the world population (http://www. fao.org/faostat). A significant increase in wheat yield is required to meet the food needs of the growing world

(c) The Author(s). 2021 Open Access This article is licensed under a Creative Commons Attribution 4.0 International License, which permits use, sharing, adaptation, distribution and reproduction in any medium or format, as long as you give appropriate credit to the original author(s) and the source, provide a link to the Creative Commons licence, and indicate if changes were made. The images or other third party material in this article are included in the article's Creative Commons licence, unless indicated otherwise in a credit line to the material. If material is not included in the article's Creative Commons licence and your intended use is not permitted by statutory regulation or exceeds the permitted use, you will need to obtain permission directly from the copyright holder. To view a copy of this licence, visit http://creativecommons.org/licenses/by/4.0/ The Creative Commons Public Domain Dedication waiver (http://creativecommons.org/publicdomain/zero/1.0/) applies to the data made available in this article, unless otherwise stated in a credit line to the data. 
population [5, 6]. Common wheat is a moderately salttolerant crop and can produce a reduced yield when grown in saline soil $[1,6,7]$. Therefore, it is critical to understand the salt-stress response- and adaptationrelated mechanisms in common wheat and to utilize the salt tolerant varieties in wheat breeding and application of genetic resource.

Some salinity adaptation-related mechanisms, such as osmotic adjustment, tissue-tolerance processes and $\mathrm{Na}^{+}$exclusion, have been elaborated in rice, maize and barely [1, 2, 8, 9]. However, studies of salinity tolerance in wheat are limited owing to its large $(\sim 17$ Gb), complicated and hexaploid (AABBDD) genome $[10,11]$. Notably, with the development of highthroughput sequencing technology, increasing whole genome-based information has been released for wheat [12]. Simultaneously, many single nucleotide polymorphisms (SNPs) were identified and placed on SNP chips, which have become powerful genotyping platforms in genome-wide association studies (GWASs) and quantitative trait loci (QTL) mapping [5]. For instance, QTLs that control grain shape and size were revealed by $\mathrm{Wu}$ et al. [13] in wheat Yanda1817/Beinong6 recombinant inbred lines (RILs) using the wheat Infinium iSelect $9 \mathrm{~K}$ SNP genotyping assay. Ma et al. [14] performed a GWAS for six yield-related traits in a breeding population derived from Xiaoyan 6 using the wheat $90 \mathrm{~K}$ array. A range of diploid, tetraploid and hexaploid wheat accessions were characterized by a high density wheat $820 \mathrm{~K}$ array, and a wheat consensus map was constructed using 56,505 SNP markers [15]. Recently, a new wheat SNP array, Wheat660K, was designed by the Chinese Academy of Agricultural Sciences. Wheat660K array contains $\sim 630,517$ SNPs generated from the low coverage sequencing of 192 common wheat and related species accessions (https://wheat. pw.usda.gov/ggpages/topics/Wheat660_SNP_array_ developed_by_CAAS.pdf). With the advantages of genome specificity and high density, the Wheat660K array has a wide range of possible applications in gene discovery, haplotype mapping, genomic selection and evolutionary studies. For example, a major effect QTL that might be a new adult plant-resistance gene to stripe rust was detected in wheat cultivar Yaco "S" using the Wheat660K SNP chip [16]. Cui et al. [11] characterized a major stable QTL for kernel number per spike on a high-density genetic map of hexaploid wheat using the Wheat660K array. Markers that are closely linked to the dwarfing gene Rht24 were identified by Tian et al. [17] utilizing the Wheat660K array.

GWASs are based on linkage disequilibrium, and the method has become a popular and efficient tool for gene discovery and marker development for complex traits
[18]. With several advantages, such as the use of diverse germplasms as materials and the capability to capture superior alleles that have been missed by breeding practices, GWASs have been widely used to dissect complex genetic mechanisms regulating biotic and abiotic stress tolerance in wheat $[16,19,20]$. For instance, Riaz et al. [21] performed a GWAS using 10,748 DArT-seq markers in a diverse panel of 295 bread wheat accessions for leaf rust resistance. Mwadzingei et al. [22] assessed the various agronomic traits of 93 diverse bread wheat genotypes under drought-stress conditions. However, limited research to identify major stable loci of wheat under salt-stress conditions has been conducted using GWASs. Hussain et al. [23] identified QTLs linked with micronutrient concentrations in wheat $F_{2}$ lines under salt-stress conditions at the seedling stage. Salt tolerance QTLs have been identified in winter wheat cultivars at germination and seedling stages using GWASs [20]. Furthermore, most previous studies were confined to the wheat seedling stage. Limited studies focused on the wheat adult stage.

Here, the performances of 191 wheat accessions were evaluated during three consecutives growing seasons at Nanpi eco-agricultural experimental station, which possesses the typical salinization soil in the low plain around Bohai Sea. And Wheat660K array was used to identify SNP markers associated with eight phenotypic traits of the wheat accessions under different salinity conditions, with the aims of providing valuable information on important allelic variations affecting wheat yield and related traits under practical salt-stress conditions and finding usable SNP markers and varieties for wheat salt-tolerance breeding programs.

\section{Results}

Responses to salinity stress, variations and correlations between phenotypic traits

The phenotypes of 191 wheat accessions were characterized during three crop seasons (2014-2017) in low salinity (LS) and high salinity (HS) environments. Significant differences existed among accessions for all the traits in the two different salinity treatments. Compared with LS conditions, the mean values for the eight phenotypic traits decreased to different degrees in HS treatment, indicating more significant inhibitory effects on the growth of wheat accessions under HS conditions (Table 1). Additionally, correlation co-efficient analyses were conducted among the three field experiments for the same trait under the same treatment. All the adult-stage traits had highly significant positive correlations, implying the moderate repeatability for these traits in field experiments (Table S2). Estimations of heritability for all the phenotypic traits showed moderate to high heritability 
Table 1 Descriptive statistics and variance parameters estimated for eight traits studied on 191 wheat accessions under low and high salinity conditions from 2015 to 2017

\begin{tabular}{|c|c|c|c|c|c|c|c|}
\hline & & \multicolumn{2}{|c|}{ Descriptive } & \multicolumn{4}{|c|}{ Variance parameters } \\
\hline & & Mean & Range & $\overline{\mathbf{G}}$ & $\mathrm{G} \times \mathrm{E}$ & $E$ & $H^{2}(\%)$ \\
\hline \multirow[t]{2}{*}{$\mathrm{PH}(\mathrm{cm})$} & LS & 76.1 & $49.80-149.00$ & 85.3 & 2.6 & 2.52 & 88.58 \\
\hline & $\mathrm{HS}$ & 63.89 & $21.00-118.00$ & 48 & 12.2 & 22.1 & 56.3 \\
\hline \multirow[t]{2}{*}{ SN } & LS & 12.63 & $2.00-33.00$ & 24.1 & 16.9 & 7.98 & 29.62 \\
\hline & $\mathrm{HS}$ & 8.8 & $1.00-30.00$ & 15.5 & 38.1 & 9.55 & 25.65 \\
\hline \multirow[t]{2}{*}{$\mathrm{SL}(\mathrm{cm})$} & LS & 8.25 & $0.50-14.00$ & 34.9 & 38.4 & 4.38 & 56.83 \\
\hline & $\mathrm{HS}$ & 7.87 & $3.50-13.20$ & 35.2 & 24.1 & 17.5 & 46.52 \\
\hline \multirow[t]{2}{*}{ KPS } & LS & 49.77 & 18.00-108.00 & 33.8 & 13.3 & 7.15 & 39.5 \\
\hline & $\mathrm{HS}$ & 49.03 & $10.00-109.00$ & 30.5 & 2.65 & 21.2 & 31.59 \\
\hline \multirow[t]{2}{*}{$\mathrm{BM}(\mathrm{g})$} & LS & 45.17 & $4.00-109.48$ & 26.9 & 6.35 & 10.2 & 29.48 \\
\hline & $\mathrm{HS}$ & 30.01 & $0.72-91.72$ & 14.3 & 33.1 & 12.5 & 21.95 \\
\hline \multirow[t]{2}{*}{ YPP (g) } & LS & 19.87 & $2.30-52.07$ & 25.3 & 0.37 & 11.6 & 26.02 \\
\hline & $\mathrm{HS}$ & 14.03 & $0.31-41.97$ & 17.2 & 17.6 & 14.3 & 21.18 \\
\hline \multirow[t]{2}{*}{ GN } & LS & 486.94 & $54.00-1342.00$ & 21.6 & 18.8 & 9.7 & 27.56 \\
\hline & $\mathrm{HS}$ & 344.23 & $31.00-1360.00$ & 18.2 & 24.6 & 14.3 & 24.4 \\
\hline \multirow[t]{2}{*}{ TKW (g) } & LS & 41.77 & $15.62-71.96$ & 25.1 & 57.6 & 8.09 & 60.03 \\
\hline & $\mathrm{HS}$ & 41.39 & $7.80-63.65$ & 34.9 & 26.1 & 13.9 & 47.86 \\
\hline
\end{tabular}

PH plant height, $S N$ spike number, $S L$ spike length, $K P S$ kernels per spike, $G N$ grain number, TKW thousand kernels weight, YPP yield per plot, $B M$ biological mass, $G$ genotype, E environment, $G \times E$ genotypexenvironment, $H^{2}$ broad-sense heritability

levels. All the phenotypic traits showed higher heritability levels under LS conditions than under HS conditions (Table 1). PH showed the highest heritability levels under LS $\left(H^{2}=88.58 \%\right)$ and HS $\left(H^{2}=56.30 \%\right)$ conditions. SL and KPS have moderate and relatively stable heritability levels, with $H^{2}$ values of 56.83 and 39.5\% under LS conditions and 46.52 and $31.59 \%$ under HS conditions, respectively. Compared with the other traits, YPP and GN showed similar but lower heritability level under LS and HS conditions (Table 1). Pearson's co-efficient of correlation between traits was calculated based on data averaged across 3 years under the two salinity conditions (Table 2). PH showed significantly positive correlations with SN, SL, KPS, BM, YPP and GN under both salt-stress conditions, and the correlation coefficients between $\mathrm{PH}$ and both $\mathrm{BM}$ and GN were comparatively higher than those between $\mathrm{PH}$ and other traits in the two salinity environments. TKW showed significantly negative correlations with PH, SN, KPS and GN, but was positively correlated with SL and YPP under both salinity treatments. In addition, BM and GN showed extremely high and positive correlations with YPP under LS and HS conditions. The correlations between yield and its components (SN, KPS and TKW) were significantly positive under both salinity conditions. Importantly, the correlation coefficients between YPP and SN were highest under both conditions, while the correlation coefficients between YPP and TKW were lower, compared with those between YPP and KPS. Interestingly, compared with LS treatment, the correlation coefficients between YPP and both SN and KPS slight increased under HS treatment.

\section{SNP genotyping}

Based on the quality preprocessing results provided by PLINK software (http://zzz.bwh.harvard.edu/plink/data. shtml), 8451 and 221,878 SNPs were removed for having call rates less than $80 \%$ and minor allele frequencies less than 0.05 , respectively. No accession was removed for low genotyping (MIND >0.1). Finally, 191 accessions containing 387,657 SNPs were retained for further analyses. And among these, 322,590 SNP markers were mapped on the Wheat660K consensus maps (Prof.Jizeng Jia, pers.comm.). The numbers of SNPs presented on each wheat chromosome were provided in Table S3. In total, 740,124 variation-containing alleles were detected by 387,657 SNPs among the 191 cultivars (Table S3). The range of the mean allele numbers on the 21 wheat chromosomes was from 1.38 to 3.25 . The greatest mean

Table 2 Correlation analysis of different traits for 191 common wheat accessions under low and high salinity treatments

\begin{tabular}{|c|c|c|c|c|c|c|c|c|c|}
\hline & $\mathrm{PH}$ & SN & $S L$ & KPS & BM & YPP & GN & TKW & \\
\hline$\overline{\mathrm{PH}}$ & & $0.494^{* *}$ & $0.405^{* *}$ & $0.362^{* *}$ & $0.510^{* *}$ & $0.415^{* *}$ & $0.553^{* *}$ & $-0.358^{* *}$ & $\overline{\mathrm{PH}}$ \\
\hline SN & $0.335^{* *}$ & & -0.08 & 0.028 & $0.811^{* *}$ & $0.785^{* *}$ & $0.891^{* *}$ & $-0.162^{*}$ & SN \\
\hline$S L$ & $0.284^{* *}$ & -0.079 & & $0.331^{* *}$ & $0.282^{* *}$ & $0.260^{* *}$ & $0.164^{*}$ & $0.151^{*}$ & $S L$ \\
\hline KPS & $0.314^{* *}$ & -0.093 & $0.262^{* *}$ & & $0.327^{* *}$ & $0.317^{* *}$ & $0.398^{* *}$ & $-0.303^{* *}$ & KPS \\
\hline BM & $0.496^{* *}$ & $0.764^{* *}$ & $0.164^{*}$ & $0.285^{* *}$ & & $0.964^{* *}$ & $0.897^{* *}$ & 0.12 & BM \\
\hline YPP & $0.303^{* *}$ & $0.740^{* *}$ & $0.156^{*}$ & $0.238^{* *}$ & $0.941^{* *}$ & & $0.889^{* *}$ & $0.205^{* *}$ & YPP \\
\hline GN & $0.447^{* *}$ & $0.859^{* *}$ & 0.032 & $0.356^{* *}$ & $0.870^{* *}$ & $0.855^{* *}$ & & $-0.218^{* *}$ & GN \\
\hline TKW & $-0.308^{* *}$ & $-0.227^{* *}$ & $0.223^{* *}$ & $-0.271^{* *}$ & 0.079 & $0.215^{* *}$ & $-0.293^{* *}$ & & TKW \\
\hline
\end{tabular}

The upper triangular matrix represents high salinity; the lower triangular matrix represents low salinity

$P H$ plant height, $S N$ spike number, $S L$ spike length, KPS kernels per spike, GN grain number, TKW thousand kernels weight, $Y P P$ yield per plot, $B M$ biological mass ${ }^{*}$ represents significant difference determined at $p<0.05$, ** represents significant difference determined at $p<0.01$ 
allele numbers were on chromosomes $6 \mathrm{D}, 2 \mathrm{D}$ and $4 \mathrm{~A}$, successively. Chromosome 3B had the lowest mean allele number (Table S3).

\section{Genetic structure and linkage disequilibrium}

Different methods were used to analyze the population structure. The neighbor-joining method based on Nei's standard genetic distance [24] was used to classify the 191 accessions, and it indicated that they were divided into two groups (Fig. 1a). The first group (45) mainly consisted of improved varieties from Shaanxi. The second group (146) was mainly comprised of improved varieties originating from Beijing, Hebei, Henan and Shandong. These two groups were further confirmed by PCA and population structure analyses. When the number of subpopulations $(K \mathrm{~s})$ was plotted against the $\Delta K$ calculated using software Structure, the highest $\Delta K$ was observed at $K=2$ (Fig. 1b and e), indicating that the 191 accessions could be divided into two subgroups. The PCA also showed two distinct clusters (Fig. 1c). According to the phylogenetic tree
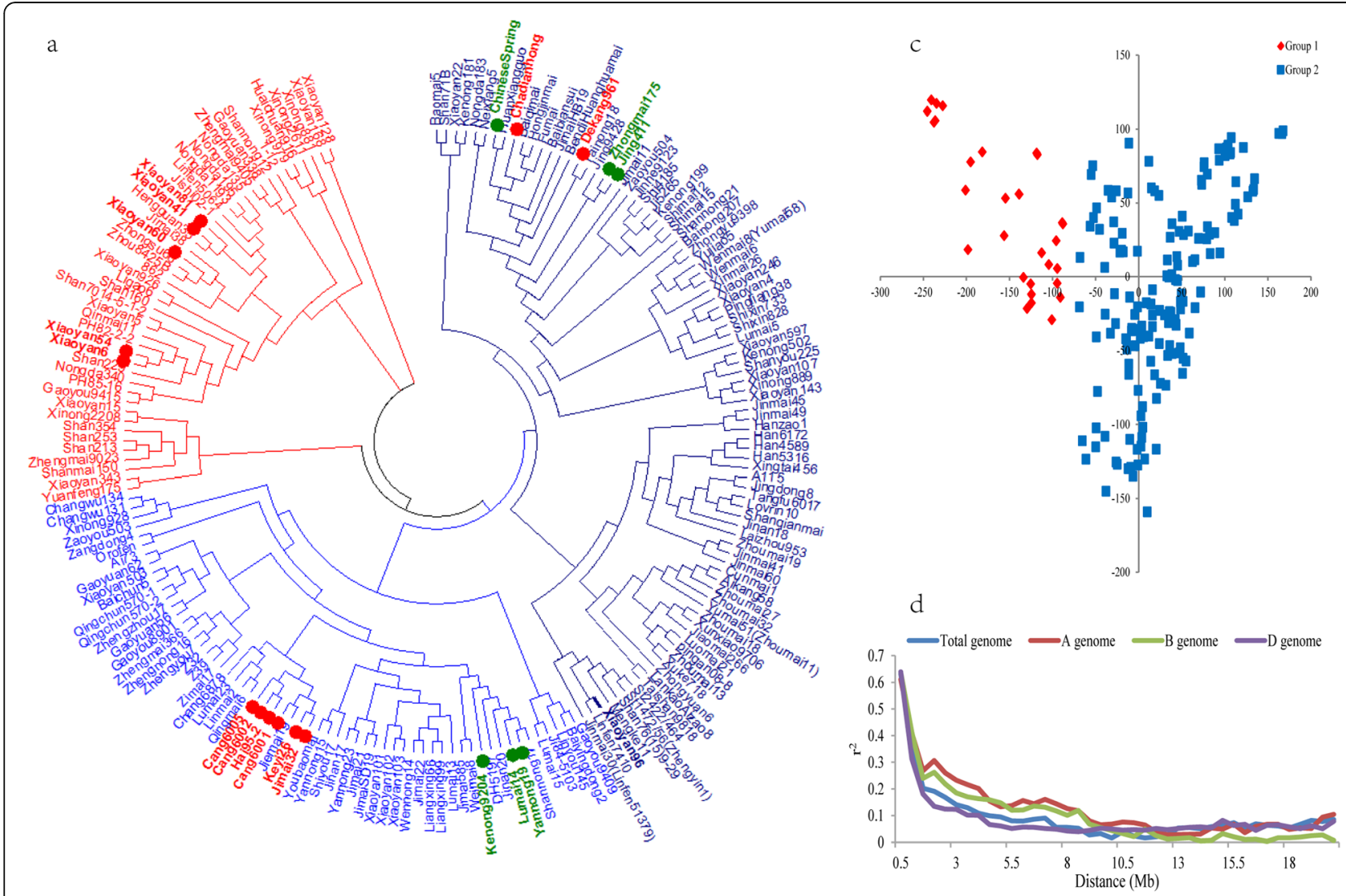

b
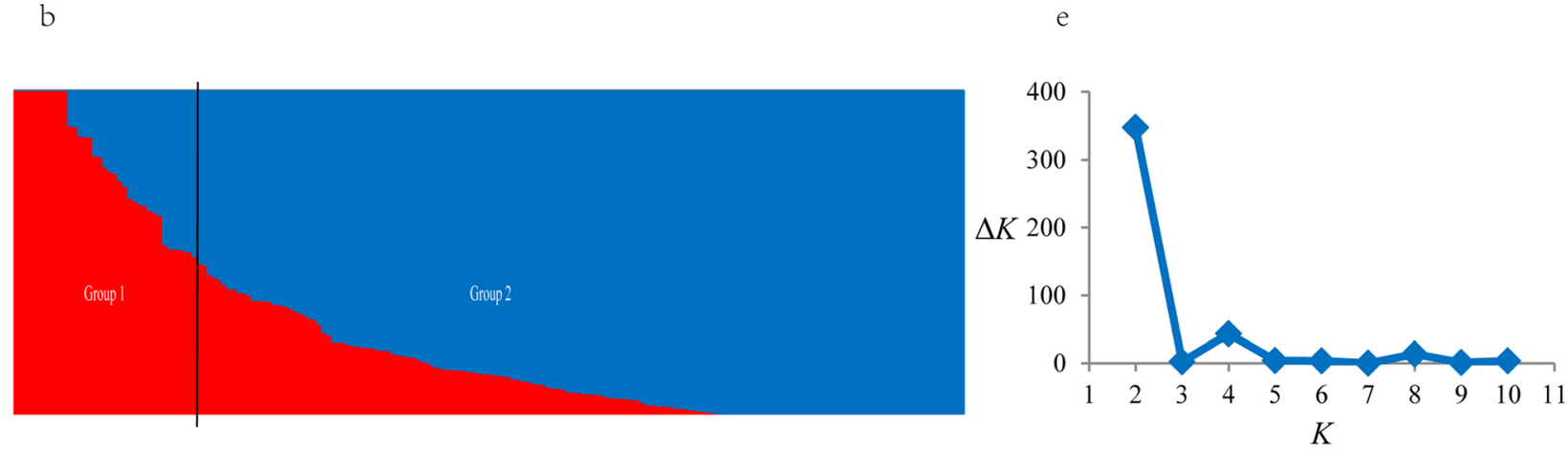

Fig. 1 Population structure of the common wheat population. a Neighbor-joining tree analysis of 191 wheat accessions. b Stacked bar plot of ancestry relationship of 191 wheat accessions when $K=2$. c Plot of the first principle component against second principle component. $\mathbf{d}$ Decay of linkage disequilibrium (LD) in the A, B, D sub-genomes and total genome of the common wheat population. e Plot of delta $K$ against putative $K$ ranging from 1 to 10 
constructed using the neighbor-joining method, the wellknown salt-tolerant wheat accessions, such as Cang 6001, Cang 6002, Cang 6005, Dekang 961, Jimai 32 and Keyi 26, clustered into group 2.

Linkage disequilibrium was calculated using 153,725, 184,755, and 49,177 SNP markers for the A, B, and D subgenomes, respectively. Based on the critical $r^{2}$ threshold value at 0.1 , the LD decay distance of the whole genome was approximately $5.0 \mathrm{Mb}$. The highest $\mathrm{LD}$ decay distance of $8.5 \mathrm{Mb}$ was found in the A sub-genome, followed by $8.0 \mathrm{Mb}$ in the $\mathrm{B}$ sub-genome. The $\mathrm{D}$ sub-genome has the lowest LD decay distance of $3.5 \mathrm{Mb}$ (Fig. 1d).

\section{Associations between traits and SNPs}

Association analyses were performed between the phenotypic traits at the adult stage and SNP markers. In total, 611 significantly associated signals among 389 SNPs were identified for eight phenotypic traits in the six environments at $P<1.25 \mathrm{e}-6$ (Table S4). The phenotypic variation explanation rate $\left(R^{2}\right)$ ranged from 9.14 to 68.81\% (Table S4). A total of 152 SNPs showed significant associations with the same trait in two or more environments, and 44 SNPs showed significant associations with two or more traits (Table S5). In general, 11 significantly associated loci (a $5 \mathrm{Mb}$ interval containing three or more significant associated SNPs was regarded as a locus) that might affect the growth of wheat under saltstress conditions were among the 389 SNPs associated with PH, SL, SN, YPP, GN, BM and TKW (Fig. 2).

\section{Plant height}

Up to 141 significant SNPs associated with $\mathrm{PH}$ were detected and mainly distributed on chromosomes $2 \mathrm{~B}, 2 \mathrm{D}, 3 \mathrm{D}, 4 \mathrm{~A}, 4 \mathrm{D}$, 5A, 6B, 7B and 7D (Table S4). Of these, 79 SNPs were detected in at least two environments under LS conditions and were mainly located on chromosome 5A (Table S5). Significant associations were detected in one environment under HS conditions for eight SNPs related to $\mathrm{PH}$, which were located on chromosome 4A (2), 4D (4) and 5A (2) (Table S5). One SNP locus named $Q P h-5 A 1$, which contained four SNPs and was located on chromosome 5A at 535.91-536.80 $\mathrm{Mb}$, was significantly associated with $\mathrm{PH}$ in $15 \mathrm{LS}$ and $15 \mathrm{HS}$, explaining $44.46-67.67 \%$ of the phenotypic variation. More importantly, one SNP of QPh-5A1 was significantly associated with YPP in 15HS. On chromosome 4D, four SNPs located in the interval $16.93-19.29 \mathrm{Mb}$ (Fig. 2), defined as QPh-4D, were associated with $\mathrm{PH}$ in $17 \mathrm{HS}$ and explained $52.81-53.62 \%$ of the phenotypic variation.

\section{Spike length}

A total of 80 significant SNPs were associated with SL and distributed on chromosomes $1 \mathrm{~A}, 1 \mathrm{~B}, 2 \mathrm{~A}, 2 \mathrm{D}, 3 \mathrm{~B}, 3 \mathrm{D}, 5 \mathrm{~B}$, 5D, 6D and 7A (Table S4). Among them, nine SNPs on chromosome $1 \mathrm{~B}$ and three SNPs on 7A were detected in two environments under LS conditions (Table S5). Meanwhile, four SNPs on chromosomes 1A (1), 1B (1), 2A (1) and 2D (1) were detected in two environments under HS conditions (Table S5). The important loci associated with SL were mainly located on chromosomes $1 \mathrm{~B}, 3 \mathrm{~B}, 5 \mathrm{~B}$ and $7 \mathrm{~A}$ based on the repeatability scores. Locus QSL-1B, including 11 significant SNPs in 15LS and 17LS, was located at 674.96-675.13 Mb on chromosome 1B (Fig. 2) and explained $16.38-23.12 \%$ of the phenotypic variation. Locus QSl-3B, consisting of five SNPs, was associated with SL in $15 \mathrm{HS}$ and located at $62.13-62.14 \mathrm{Mb}$ on chromosome 3B (Fig. 2) and explained $12.18-12.82 \%$ of the phenotypic variation. On chromosome 5B, four SNPs located at 574.06$578.35 \mathrm{Mb}$ (Fig. 2), named as Q-5B1, were associated with the relative value of SL (16HS/16LS) and explained 12.94$14.29 \%$ of the phenotypic variation. Importantly, two SNPs of Q-5B1 were significantly associated with the relative values of BM, GN and YPP. Locus QSl-5B2, containing 21 SNPs, was located in the interval $583.48-584.89 \mathrm{Mb}$ on chromosome $5 \mathrm{~B}$ (Fig. 2). It was significantly associated with the relative value $(16 \mathrm{HS} / 16 \mathrm{LS})$ of $\mathrm{SL}$ and could explain $13.03-15.28 \%$ of the phenotypic variation (Table S5). Furthermore, one SNP of QSl-5B2 was significantly associated with the relative values (16HS/16LS) of BM (Table S5). Locus Q-7A, involving 12 SNPs, was mapped at 22.75$22.88 \mathrm{Mb}$ on chromosome 7A (Fig. 2), among which ten SNPs were significantly associated with SL in $15 \mathrm{LS}$ and 16LS, explaining $20.20-28.47 \%$ of the spike length variation. In total, seven SNPs of Q-7A were significantly associated with YPP in 15LS and 16LS and two SNPs of Q-7A were significantly associated with GN in $15 \mathrm{HS}$ and $16 \mathrm{HS}$ (Table S5).

\section{Grain number}

In total, 60 SNPs were significantly associated with GN and were mainly located on chromosomes $2 \mathrm{~A}, 3 \mathrm{~A}, 5 \mathrm{~B}$ and 7A (Table S4). A comparison of the associated SNPs for SN and GN showed abundantly common SNPs from chromosome $5 \mathrm{~B}$ that were accumulated at the common locus Q-5B3 (690.08-690.70 Mb) (Fig. 2). At this locus, 34 SNPs were detected in LS environments for GN, and five SNPs were detected under both LS and HS conditions. Notably, the correlation analysis of pairwise traits showed extremely high co-efficient of correlation between GN and SN, with values were 0.859 and 0.891 under LS and HS treatments, respectively.

\section{Biological mass}

Up to 18 significant SNPs were associated with BM, and they were mainly distributed on chromosomes $4 \mathrm{~A}, 4 \mathrm{~B}$, 5A and 5B (Table S4). Of these, nine and three SNPs on chromosome $5 \mathrm{~B}$ were detected in $15 \mathrm{LS}$ and $16 \mathrm{HS} / 16 \mathrm{LS}$ and could explain $10.04-13.90 \%$ and $12.61-12.80 \%$ of the phenotypic variation, respectively. 


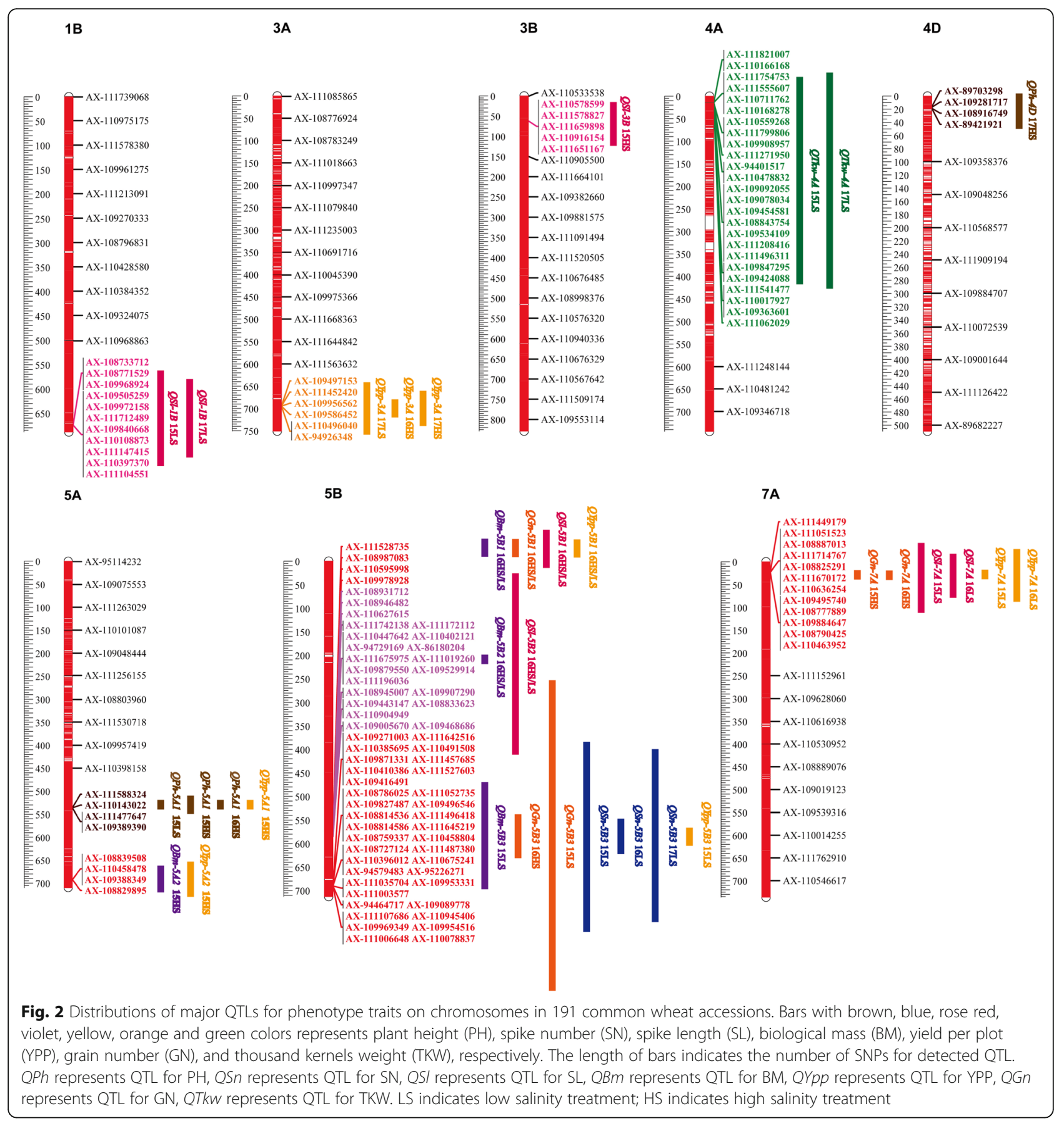

\section{Yield per plant}

A total of 48 significant SNPs were associated with YPP and were mainly distributed on chromosomes $2 \mathrm{D}, 3 \mathrm{~A}, 5 \mathrm{~A}$, $5 \mathrm{~B}$ and 7A (Table S4). Of them, six SNPs, forming locus QYpp-3A, were located on chromosome 3A at 694.01$694.96 \mathrm{Mb}$. The locus was associated with YPP in 16HS, 17LS and 17HS with a phenotypic variation of 11.36$16.32 \%$ (Fig. 2). In addition, four SNPs, composing locus Q-5A2, were located on chromosome $5 \mathrm{~A}$ at 692.16$692.39 \mathrm{Mb}$ and detected in $15 \mathrm{HS}$, with a phenotypic variation of $10.69-12.70 \%$ (Fig. 2). The SNPs of Q-5A2 were significantly associated with BM in $15 \mathrm{HS}$. The common locus associated with YPP and SL was Q-7A (22.75$22.88 \mathrm{Mb})$, which was observed on chromosome $7 \mathrm{~A}$ (Fig. 2).

\section{Spike number}

As many as 68 significant SNPs were associated with SN and were mostly located on chromosomes $1 \mathrm{~A}, 1 \mathrm{~B}, 2 \mathrm{~A}$, 2B, 5A, 5B, 5D, 6D and 7B (Table S4). Of these, 19 SNPs 
on chromosome 5B were detected in at least two environments under LS conditions, while two SNPs on chromosome 5A were detected in at least two environments under HS conditions. Locus Q-5B3 consisting of 36 SNPs was found on chromosome $5 \mathrm{~B}$ at 690.08$690.70 \mathrm{Mb}$, and 24 SNPs in this locus were associated with SN in 15LS, 16LS and 17LS (Fig. 2) and could explain $17.29-32.82 \%$ of the phenotypic variation. Moreover, the SNPs of Q-5B3 were almost significantly associated with not only GN in 15LS (34) and 16HS (5), but BM in 15LS (9) (Table S5).

\section{Thousand-kernel weight}

Totally, 31 significant SNPs associated with TKW were mainly distributed on chromosomes 3B, 3D, 4A, 4B and 7B (Table S4). Among these, the largest number of SNPs (up to 25) was from chromosome 4A. These SNPs, forming locus $Q T k w-4 A$ at $14.68-16.28 \mathrm{Mb}$, were detected in 15LS and 17LS and could explain 18.60$35.57 \%$ of the phenotypic variation.

\section{Phenotypic effects of alleles in the natural population}

A $t$ test was performed to verify the favorable alleles in the natural population based on the significantly associated SNPs, and some loci in this study were identified as possibly affecting the agronomic traits of wheat under salt-stress conditions. For instance, accessions with favorable alleles at loci QSl-1B (674.96$675.13 \mathrm{Mb}), \quad Q S l-3 B(62.13-62.14 \mathrm{Mb})$ and QSl-5B2 (583.48-584.89 Mb) showed longer SLs (increased by $0.54-0.97 \mathrm{~cm}$ with LS and by $0.57-2.44 \mathrm{~cm}$ with $\mathrm{HS}$ ). Favorable alleles of locus QTkw-4A (14.68-16.28 Mb) increased the TKW by $4.06-5.32 \mathrm{~g}$ under LS and by 2.49-5.95 g under HS. Favorable alleles of locus $Q P h-$ $4 D(16.93-19.29 \mathrm{Mb})$ increased $\mathrm{PH}$ by $3.42-4.57 \mathrm{~cm}$ under LS and by $4.21-4.31 \mathrm{~cm}$ under HS. Accessions with favorable alleles at locus Q-5B1 (574.06-578.35 $\mathrm{Mb}$ ) have longer SLs (by $1.06-2.46 \mathrm{~cm}$ ) and greater BMs (by 4.72-5.45 g), GNs (by 23.80-65.29) and YPPs (by $2.58-8.69 \mathrm{~g}$ ) under HS. Accessions with favorable alleles at locus Q-5B3 (690.08-690.70 Mb) have greater BMs (by 1.49-4.54 g under LS and by 1.44$1.89 \mathrm{~g}$ under HS), SNs (by $0.46-1.50$ under LS and by 0.35-0.64 under HS), GNs (by 14.49-60.75 under LS and by 16.16-25.68 under HS) and YPPs (by 2.71$5.73 \mathrm{~g}$ under LS and by $2.43-2.88 \mathrm{~g}$ under HS). Favorable alleles of locus $Q-7 A(22.75-22.88 \mathrm{Mb})$ increased SL and YPP by $0.71-1.28 \mathrm{~cm}$ and $2.16-3.39 \mathrm{~g}$ under $\mathrm{LS}$, respectively, and increased SL by $1.07-1.11 \mathrm{~cm}$ under HS (Table S6).

The frequencies of the alleles of the above key loci ranged from 5.76 to $93.72 \%$ (Table S6). An analysis of the distributions of favorable alleles indicated that introduced varieties possessed the highest average number of favorable alleles, followed by improved cultivars. The average number of favorable alleles in landrace was the lowest (Fig. S1a). Except accessions from Gansu and Sichuan, which were mostly landraces, accessions from Hebei, Henan and Shaanxi had comparatively higher average numbers of favorable alleles, followed by the cultivars from Shandong, Beijing and Shanxi. However, cultivars from Qinghai had the lowest average number of favorable alleles (Fig. S1b). Thus, it was believed that the introduced varieties and the improved cultivars should be utilized to improve these yield-related traits in salinity tolerant wheat cultivars. In addition, the favorable alleles of the same associated trait varied for some well-known cultivars. For example, although accessions Kenong 181, Liangxing 99, Zaoyou 504 and Jinhe 9123 had similar SL, Kenong 181 and Liangxing 99 contained the favorable alleles from loci QSl-1B, QSl-5B2 and Q-7A, whereas Zaoyou 504 and Jinhe 9123 had the favorable alleles from loci QSl-1B, QSl-3B1, and Q-7A. Besides, the YPP of landrace Chadianhong and Baiqimai was similar. Chadianhong contained the favorable alleles from loci Q-5A2 and Q-7A, while Baiqimai had the favorable alleles from loci QYpp-3A and Q-5A2.

\section{Development of Kompetitive Allele Specific PCR (KASP) markers for the important loci}

In total, 14 KASP markers were designed and used to detect polymorphisms in ZX-RIL and HL-DH populations (Table S8). Eight KASP markers were polymorphic. Of these, four (kasp-5695, kasp-9337, kasp-6491 and kasp-4516) showed polymorphisms in ZX-RIL population, two (kasp-9179 and kasp-4767) were polymorphic in HL-DH population, and two (kasp-8827 and kasp9508) were polymorphic in both ZX-RIL and HL-DH populations. Based on the genotyping results of each KASP marker, a $t$ test was conducted for corresponding traits in the related DH and RIL populations.

KASP marker kasp-9508, which came from locus Q-5A2, was polymorphic in ZX-RIL as well as HL$\mathrm{DH}$ populations. In HL-DH population, kasp-9508 was significantly correlated with $\mathrm{PH}, \mathrm{BM}$ and TKW in two environments (LS and HS) and was correlated with YPP under HS conditions (Fig. S2a-d). For the locus Q-7A, markers kasp-9179 and kasp-4767 were polymorphic in HL-DH population. Kasp-9179 was significantly correlated with $\mathrm{PH}$ in two environments (LS and HS), with SL under LS conditions, and with $\mathrm{BM}$ and YPP under HS conditions (Fig. S2e-h). Kasp-4767 was significantly correlated with $\mathrm{PH}, \mathrm{BM}$ and YPP under HS conditions and with SL under LS conditions (Fig. S2i-l). Thus, loci $Q-5 A 2$ and $Q-7 A$ should be stable and pleiotropic loci affecting $B M$, $\mathrm{PH}, \mathrm{SL}, \mathrm{TKW}$ and YPP under salt-stress conditions. 


\section{Discussion}

Comparison with previous studies and gene prediction of key loci

In the present study, 191 wheat accessions were genotyped using the Axiom Wheat660K array, which were used to identify genomic regions and SNPs associated with agronomic traits under saline conditions using a GWAS. SNPs significantly associated with plant type, spike characteristics, grain yield and its component traits were mainly observed on chromosomes $1 \mathrm{~B}, 3 \mathrm{~A}, 3 \mathrm{~B}, 4 \mathrm{~A}$, $4 \mathrm{D}, 5 \mathrm{~A}, 5 \mathrm{~B}$, and 7A. Moreover, the number of significantly associated SNPs identified under LS conditions was much more than those under HS conditions, which was similar to the results obtained under drought-stress conditions $[22,25]$, indicating that genotype by environment interactions could highly influence the salinity tolerance capability of wheat cultivars. In total, 11 loci located on chromosomes 1B (1), 3A (1), 3B (1), 4A (1), $4 \mathrm{D}(1), 5 \mathrm{~A}(2), 5 \mathrm{~B}(3)$ and 7A (1) were identified to play important roles in modulating the agronomic traits of wheat cultivars under salt-stress (Table S6).

QTLs have been identified for the same or related traits at similar positions [22, 26-29], which confirmed the importance of the loci identified in the present study (Table S7). For example, PH is a crucial agronomic trait for morphogenesis and grain yield formation in wheat [30]. Factors that might influence plant height include Mendelian and quantitative genes that are distributed on all 21 chromosomes [30-33]. More than 20 major genes influencing $\mathrm{PH}$ have been identified and designated as Rht genes [32, 34-36]. The well-known Rht4, Rht8, Rht5, Rht-B1, RhtD1, Rht9, Rht12 and Rht13 genes are located on chromosomes 2BL, 2DS, 3BS, 4BS, 4DS, 5AL, $5 \mathrm{AL}$ and $7 \mathrm{BS}$, respectively $[14,37,38]$. During common breeding practices, short genotypes are selected for their lodging resistance. However, in the present study, $\mathrm{PH}$ had a consistent positive correlation with YPP under LS and HS conditions, which corroborated similar results obtained under different stress-related environments [39-41]. Here, locus QPh-4D was identified on chromosome $4 \mathrm{D}$ at $16.93-19.29 \mathrm{Mb}$ under $\mathrm{HS}$ conditions and was located in approximately the same region as $R h t D 1$ based on a comparison with the physical positions of QTLs detected in previous studies [27, 30, 42, 43]. In addition, QTL mapping results of HL-DH population also validated that locus $Q P h-4 D$ was located in a QTL interval (AX-89703298-AX-110564616) affecting $\mathrm{PH}$ under LS conditions (Fig. 3a, b) explaining $25.90 \%$ of the phenotypic variation (Table 3 ). The positive additive effect was from Hanxuan10, and lines with the favorable allele GG in AX-89421921 also showed higher PHs in the DH population, which was consistent with the GWAS results (Table 3, Fig. 3c, d). Another locus, QPh$5 A 1$, was located on chromosome $5 \mathrm{~A}$ at $535.91-536.80$
Mb under LS and HS treatments. Díaz et al. [44] mapped a QTL $(485.83 \mathrm{Mb})$ affecting $\mathrm{PH}$ and SL in the interval Xmwg522-Xcdo412c on chromosome 5A by analyzing the ITMI wheat mapping population's response to salinity stress. But this QTL was far away from $Q P h-5 A 1$. Based on the genome sequence from cultivar Chinese Spring (IWGSC V1.1), nine interesting genes were found in the position interval 535.91-536.80 Mb. Gene predication and functional annotation indicated that these genes were related to disease resistance genes and U-box E3 ubiquitin ligase. During the past years, several QTLs conferring disease resistance have been detected in wheat, and studies indicated that these resistance genes not only had effects on disease severity, but also affected growth and yield of wheat [45]. For example, Zheng et al. [46] mapped a large-effect QTL conferring Fusarium crown rot resistance in hexaploid wheat and found that the QTL had significant effects on plant height and heading date. While, reports suggested that the U-box E3 ligases played important roles in abiotic stress response. For instance, Min et al. [47] suggested that CaPUB1, a hot pepper U-box E3 ubiquitin ligase could enhance the cold tolerance of transgenic rice.

In this study, TKW value was relatively stable under both LS and HS conditions. Locus QTkw-4A, which was significantly associated with TKW under LS conditions, was identified on chromosome $4 \mathrm{~A}$ at $14.68-16.28 \mathrm{Mb}$. A common QTL (Xgwm160) (719.26 Mb) controlling yield and TKW was detected in a population of $96 \mathrm{DH}$ lines under nutrient-, drought- and salt-stress conditions [39]. A classical grain weight-related gene $\mathrm{TaCWI}$ had been mapped on chromosomes 4A (610.04 Mb) and 5D $(557.95 \mathrm{Mb})$ in wheat [48]. These QTLs were all different from $Q T k w-4 A$, implying that $Q T k w-4 A$ could be a novel QTL for TKW. Gene predication and functional annotation of $Q T k w-4 A$ indicated that 15 interesting genes were located in the position interval 14.68-16.28 Mb. Furthermore, one candidate gene encoded a glycerol-3phosphate acyltransferase (GPAT; E.C. 2.3.1.15) was found. The GPAT gene has been cloned in some plant, such as Suaeda salsa, Oryza sativa, tomato, Arabidopsis, and so on [49-51]. Studies indicated that the GPAT genes were closely related to stress tolerance and seed development [49-51]. Ariizumi et al. [52] found that the content of unsaturated fatty acids increased when overexpressing the AtGPAT in rice, which could improve the rates of photosynthesis and growth of transgenic rice seedlings under low temperatures.

SL, a stable phenotypic character, showed significant positive correlations with YPP in two salt-stress environments. In this study, loci $Q S l-1 B$ and $Q S l-3 B$ were identified on chromosome $1 \mathrm{~B}$ at $674.96-675.13 \mathrm{Mb}$ and on $3 \mathrm{~B}$ at $62.13-62.14 \mathrm{Mb}$, respectively. Using the $90 \mathrm{~K}$ 
a 4D

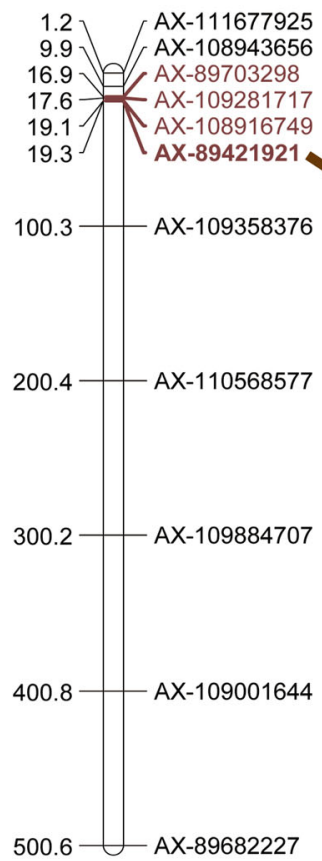

c

QPh-4D

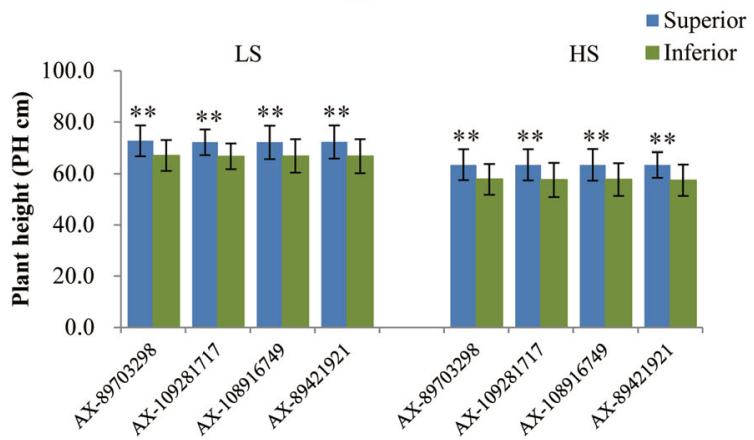

4D HL-DH

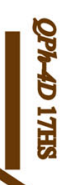

\begin{tabular}{l|l|l}
10.5 & AX-89593703 \\
12.1 & AX-111616151 \\
13.4 & AX-109816583 \\
14.2 & AX-109198827
\end{tabular}

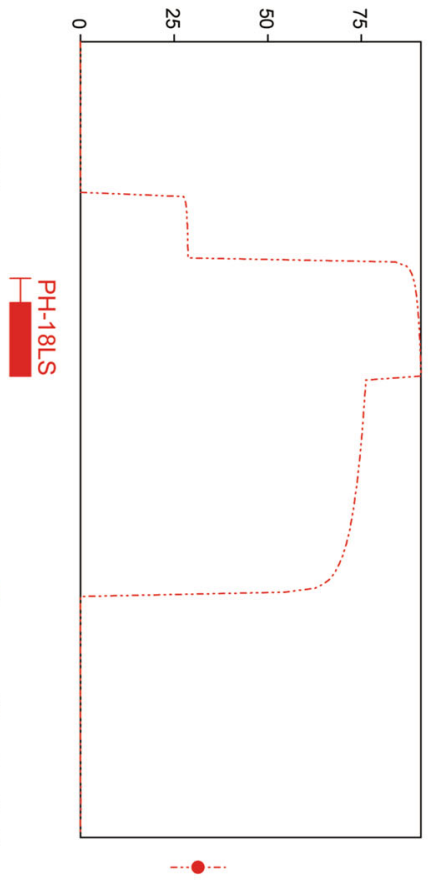

PH-18LS

d

\section{HL-DH}

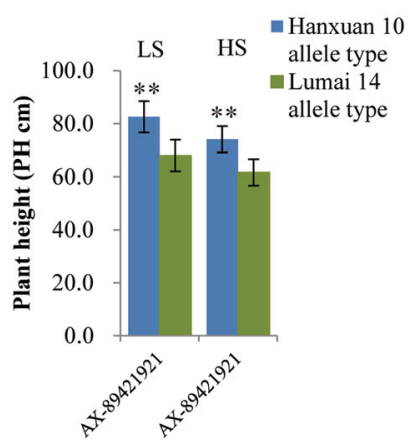

Fig. 3 QTL position on chromosome 4D for plant height (PH) in the common wheat population and HL-DH population. a Chromosome location of QPh-4D in the 191 common wheat accessions. b QTL position for PH in DH population of "Hanxuan 10xLumai 14". c The phenotype values of accessions with superior allele of $Q P h-4 D$ in the common wheat population. $\mathbf{d}$ The phenotype values of accessions with superior allele of $Q P h-4 D$ in DH population of "Hanxuan $10 \times$ Lumai 14". ** indicates significant at 0.01 level. LS, low salinity treatment; HS, high salinity treatment

Table 3 QTL intervals and agronomic traits revealed by QTL mapping in HL-DH and ZX-RIL populations

\begin{tabular}{|c|c|c|c|c|c|c|c|c|c|c|}
\hline Population & Trait & Chromosome & Position (cM) & Left marker & Right marker & LOD & PVE & Add & LeftCl & RightCl \\
\hline $\mathrm{HL}-\mathrm{DH}$ & $\mathrm{PH}-\mathrm{LS}$ & $4 \mathrm{D}$ & 18.8 & AX-89421921 & AX-110564616 & 64.35 & 25.90 & 6.87 & 17.45 & 20.50 \\
\hline ZX-RIL & SPS-HS & $5 B$ & 92 & AX-109996563 & AX-111538681 & 5.03 & 5.23 & -0.18 & 91.50 & 92.50 \\
\hline ZX-RIL & SL-HS & $7 \mathrm{~A}$ & 11 & AX-108843150 & AX-109347413 & 3.54 & 3.56 & -0.17 & 10.50 & 11.50 \\
\hline
\end{tabular}

Position (cM), distance between QTL and the top marker of each linkage map; LOD, threshold of 2.5 was set for declaring the presence of QTL; PVE (\%), phenotypic variation explained by QTL; Add Positive 'additive effect' indicated an increasing effect from Hanxuan 10 in the HL-DH population, and Zhongmai 175 in ZX-RIL population; negative 'additive effect' indicated an increasing effect from Lumai 14 in HL-DH population, and Xiaoyan 60 in ZX-RIL population PH plant height, SPS spikelets per spike, SL spike length, HL-DH the DH population of "Hanxuan 10xLumai 14", ZX-RIL the RIL population of "Zhongmai $175 \times$ Xiaoyan $60^{\prime \prime}$, LS low salinity treatment, HS high salinity treatment 
wheat SNP array, Gao et al. [27] also mapped SNPs on chromosome 1B (BS00070878_51 - Kukri_c1529_462, $22.70 \mathrm{Mb})$ and 3B (Ku_c12191_1202-Excalibur_c3556_ $520,815.48 \mathrm{Mb}$ ) associated with SL using a Zhou 8425B/ Chinese Spring RIL population. Additionally, Mwadzingeni et al. [22] identified markers associated with SL that were located on chromosome $1 \mathrm{~B}$ using 93 bread wheat genotypes under drought-stress conditions. Liu et al. [53] integrated SL-related QTLs on chromosomes 2A, $2 \mathrm{~B}$ and $6 \mathrm{~A}$ on a physical map that was constructed using 192 common wheat samples based on the $90 \mathrm{~K}$ SNP chip. The loci QSl-1B and QSL-3B for SL detected in this study were different from those previous studies and might be novel QTLs. Gene predication and functional annotation indicated that six and two candidate genes were found in the position intervals of QSl-1B and QSl$3 B$. These genes were related to keratin-associated protein and ricin B-like lectin gene, respectively. Previous studies suggested that the QTL $\left(q P E_{9-1}\right)$ for panicle encoded a protein homologous to the keratin-associated protein 5-4 family in rice [54-56]. While, lectin gene is involved in the abiotic stress response of plants [57]. For instance, the expression level of wheat lectin gene $H \mathrm{fr}-1$ was up-regulated under drought conditions, while the other lectin gene $\mathrm{Wci}_{\mathrm{i}} \mathrm{1}$ was significantly up-regulated under various stresses [57].

\section{QTL clusters for grain yield and related traits under salinity stress}

Grain yield is a complex quantitative trait and is controlled by multiple genes. Selection based on grain yield alone is simple but ineffective for wheat breeding [58]. Consequently, it is necessary for wheat breeder to identify characteristics that contribute to grain yield [41]. Thus, traits correlated with grain yield will be automatically considered as selective criteria in wheat breeding under any conditions $[40,41]$. In this study, BM, SL, GN and SN showed similar and extremely higher correlations with YPP under both LS and HS conditions (Table 2). Which was supported by Mwadzingeni et al. [22] who reported similar correlations between YPP and both BM and GN under drought-stress conditions. QTL clusters and co-localized QTLs for grain yield and component traits related to salinity stress have been reported $[26,39,59-61]$. In addition, an unusually high correlation between agronomic traits controlled by pleiotropic QTLs exists [22, 26, 60-64]. Two occurrences might be responsible for the co-localization of QTL associated with different traits: first, genes affecting various traits or the same traits were strongly linked; and second, single gene might have a series of effects on related traits or affect two or more independent traits [62]. Here, five loci affecting various grain yield-correlated traits were detected on 5A, 5B and 7A under salt-stress conditions (Tables S6).

The group-5 chromosomes appear to harbor genes associated with abiotic stress resistance, and several QTLs for grain yield and related traits under salt-stress conditions were especially located on the group- 5 chromosomes of wheat $[26,28,39,60,62]$. For example, the gene Vrn-A1 (587.41 Mb), Vrn2-5A/ZCCT1-5A (698.180559 Mb), Vrn-B1 (573.82 Mb) and Vrn-D1 $(467.18 \mathrm{Mb})$ that influences grain yield by controlling the vernalization and timing of ear emergence are located on the long arms of chromosome $5 \mathrm{~A}, 5 \mathrm{~B}$ and $5 \mathrm{D}$ $[33,65,66]$. In the present study, locus Q-5A2 located on chromosome 5A at $692.16-692.39 \mathrm{Mb}$ was identified as affecting YPP and BM under HS conditions. Three loci on chromosome 5B, Q-5B1 (574.06-578.35 Mb), QSl-5B2 (583.48-583.89 Mb) and Q-5B3 (690.08-690.70 $\mathrm{Mb})$, contained SNP clusters associated with YPP, SL, $\mathrm{SN}, \mathrm{GN}$ and BM under LS conditions. Blast search on the IWGSC database revealed that the locus Q-5A2 affecting YPP and BM was close to Vrn2-5A/ZCCT1-5A $(698.180559 \mathrm{Mb})$ [66], also the locus Q-5B1 associating with YPP, SL, GN and BM seemed to be located near to the Vrn-B1 [67]. More importantly, QTL mapping results for the ZX-RIL population validated that locus $Q$ 5B1 was located in a QTL interval (AX-109996563-AX111538681) affecting spikelets per spike under HS conditions (Table 3, Fig. S3). In addition, the locus Q-5B3 approached the QTL (QKNS.caas-5BL, 695.99 Mb) of kernel number per spike identified by Li et al. [68]. Results indicated that the co-localized QTL identified here should play a critical role in the yield and its related traits of wheat cultivars grown under stress conditions.

Gene predication and functional annotation of Q-5A2, Q-5B1, QSl-5B2 and Q-5B3 indicated that there were five, 45,19 and 12 candidate genes contained in the position intervals of each locus, respectively. These genes were related to lipid transfer protein, phytochelatin synthase, serine/threonine protein kinase and MADA-box genes. Lipid transfer proteins (LTPs) are a class of small and ubiquitous proteins and are believed to have critical roles in plant response [69, 70]. Kirubakaran et al. [70] suggested that Ltp 3F1 gene from wheat could enhance resistance against fungi in tobacco. Phytochelatin synthases (PCs) are a family of cysteine-rich thiolreactive and heavy metal-binding peptides involved in heavy metal accumulation and detoxification of plants [71]. Studies indicated that the heteroexpression of wheat TaPCS1 enhanced the $\mathrm{Cd}$ accumulation in rice shoots [71]. Serine/threonine protein kinase (STK) is a large protein family which has an important role in stress signaling and responses of plants [72]. Ge et al. [73] demonstrated that the excess-expression of TaSTK gene was capable of increasing the root growth of 
Arabidopsis thaliana under salt stress. Besides, the MADS-box family members encode transcription factors participating not only in floral organ specification, but also in plant growth and development [74]. Ma et al. [75] characterized 180 MADS-box genes in wheat and found them involved in both abiotic and biotic stress responses.

Additionally, the locus effecting YPP was located on chromosome 7A (Q-7A, 22.75-22.86 Mb) and also contained a SNP cluster associated with SL under salt-stress conditions. On chromosome 7A, Gao et al. [27] identified QTL (wsnp_Ex_c200_391493 - Ex_c52798_415, 244.27 Mb) for TKW, SN, SL and PH. Additionally, QTL mapping results in the ZX-RIL population verified that locus Q-7A could form a LD block $(475 \mathrm{~kb})$ with the QTL interval (AX-108843150-AX-109347413) that affected SL under HS treatments (Fig. 4a-c). The positive additive effect was from Xiaoyan 60, and cultivars with favorable alleles also showed longer SLs in the association population, which was consistent with the GWAS results (Table 3, Fig. 5a, b).

\section{Favorable haplotypes for wheat salt-tolerance breeding} Using the base types of SNP markers and distributions of alleles associated with a trait, some haplotypes were identified, and favorable haplotypes were determined by detecting their phenotypic values using $t$-tests. After removing the haplotypes less than $5 \%$, the main haplotypes of each locus were used for further analysis. The $t$-tests indicated that cultivars with favorable haplotypes usually had more desirable phenotypes under salt-stress conditions (Table 4, Fig. S5). In addition, the proportion of favorable haplotype for each locus was various, which indicated that these important loci had experienced different degrees of selection during wheat breeding. For example, the proportions of favorable haplotypes for locus QYpp-3A and QTkw-4A were only 5.24 and 8.90\%, respectively, which implied that these loci had not experienced strong selection.

Further comparative analyses of locus effects revealed that cultivars with three or more favorable haplotypes of loci QSl-1B, QSl-3B, QSl-5B2 and Q-7A had obviously longer SLs under LS and HS conditions (Fig. 6). About $37.17 \%$ of the population used in this study, such as landrace Fumai and improved variety Han 4589, carried three or more superior haplotypes for SL, which implied that these loci had aggregated during wheat breeding (Fig. 6). Cultivars with three favorable haplotypes at loci QYpp-3A, Q-5A2, and Q-7A produced greater yields under both salt-stress conditions (Fig. 6). However, only $3.14 \%$ of the population, such as some well-known salttolerant cultivars Cang 6001 and Cang 6005, contained three haplotypes for yield, demonstrating that these superior haplotypes had not been fully utilized during salt- tolerant wheat breeding (Fig. 6). For the co-localization loci of the group-5 chromosomes, namely Q-5A2, Q$5 B 1, Q S l-5 B 2$ and Q-5B3, cultivars with four favorable haplotypes had the highest $\mathrm{SN}, \mathrm{GN}, \mathrm{BM}$ and yield values under LS and HS conditions (Fig. 6). Not only some well-known salt-tolerant cultivars, such as Cang 6002, Cang 6005, Dekang 961, Keyi 26 and Kenong 199, but also Xiaoyan derivatives, such as Xiaoyan 6, Xiaoyan 926, Xiaoyan 54 and Xiaoyan 101, possessed four favorable haplotypes of these loci, and approximately $31.41 \%$ of cultivars contained four superior haplotypes of these co-localized loci of the group-5 chromosomes (Fig. 6), which indicated that these loci had been integrated during wheat breeding and had potential for increasing wheat salt tolerance. In general, the great differences in the distributions of favorable haplotypes in the population indicated that there were various genetic bases of salt tolerance in different varieties, and the accessions that possessed the superior haplotypes, such as cultivars Cang 6001, Cang 6002, Cang 6005, Jimai 32 and some Xiaoyan derivatives, could play key roles in wheat salttolerance breeding.

\section{Development of molecular markers for marker-assisted selection}

Some studies have emphasized that the salt-tolerance of wheat was closely linked with the ability to exclude $\mathrm{Na}^{+}$ from leaf [20, 59, 63]. Genc et al. [59] identified five QTLs associating with $\mathrm{Na}^{+}$exclusion under hydroponics-based seedling assays. The two $\mathrm{Na}^{+}$exclusion genes, Nax1 and Nax2, also have been found in durum wheat [76, 77]. However, the main QTLs identified in the present study were not co-located with mapped genes or QTLs for $\mathrm{Na}^{+}$exclusion. Reports suggested that QTLs for $\mathrm{Na}^{+}$exclusion identified in hydroponics had dinky impacts on wheat yield [63, 78] and QTLs related with salt-tolerance generally varied depending on populations and environments [63]. Actually, the QTLs associating with yield and related traits in the salt stress field can play a more important role in the wheat breeding practices. Although, with the availability of next-generation sequencing, a large number of SNPs have recently been discovered in wheat [79]. Different types of high-throughput SNP arrays have been successfully used for studying marker-trait associations in wheat populations [79]. However, the validation and utilization of these markers still represent major challenges owing to the time and labor required for genotyping huge progeny pools $[79,80]$. Recently, KASP genotyping technology was developed by LGC limited [81] for SNP genotyping. However, only a few KASP markers have been developed for important agronomic traits in wheat [14]. In this study, 14 KASP markers were successfully developed for nine loci associating with yield and related 


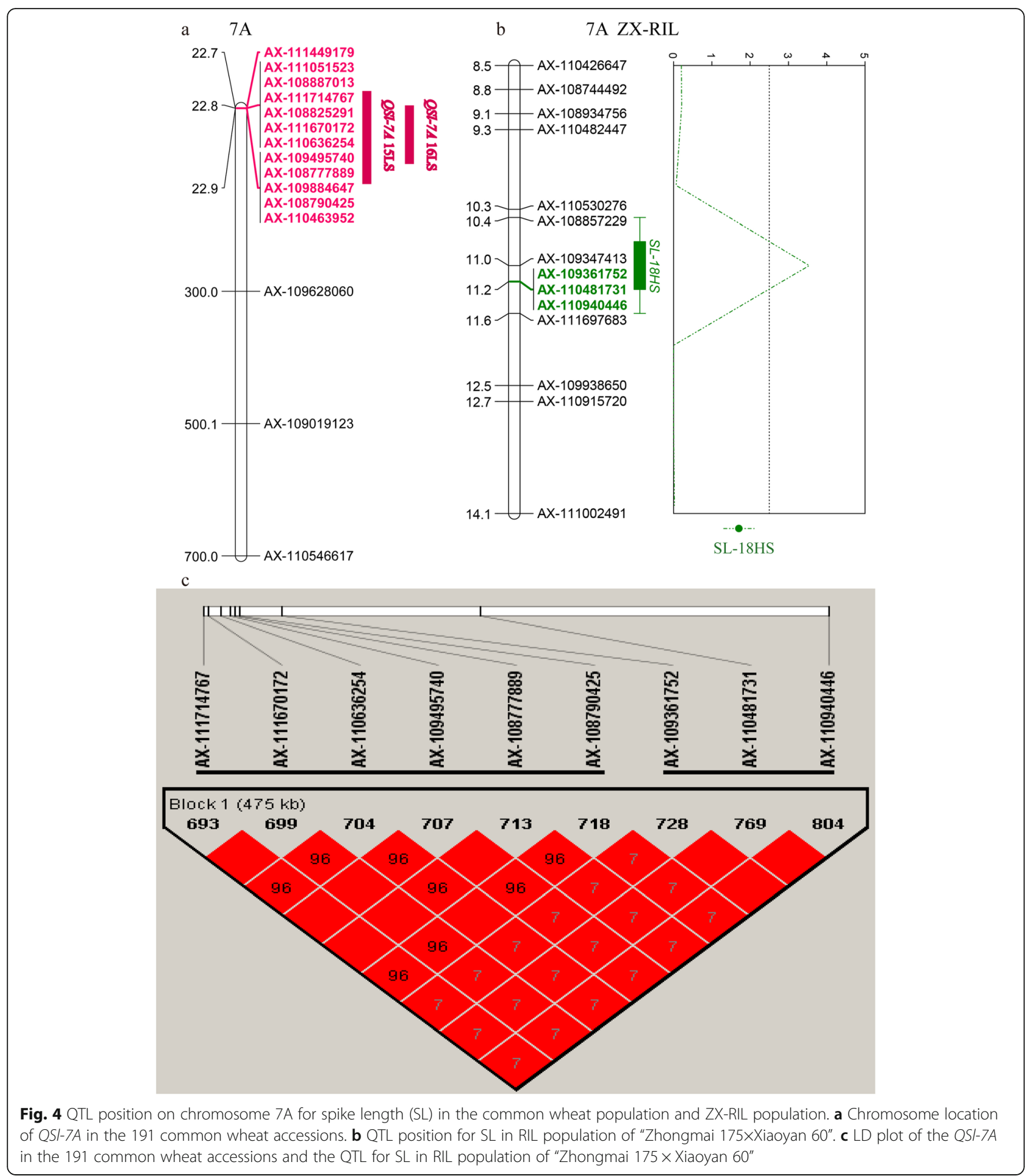

traits. These KASP markers could accurately classify two alleles in the natural population (Fig. S6). KASP markers related to BM, GN, SL and YPP came from two pleiotropic loci, namely $Q-5 A 2$, affecting BM and YPP under HS conditions, and $Q-7 A$, affecting SL and YPP under LS conditions. These KASP markers will be useful for screening salt-tolerant wheat germplasms and improving the selection efficiency of wheat salt-tolerance breeding.

\section{Conclusion}

In this study, 191 wheat accessions were evaluated in six environments for yield and related traits under low and 


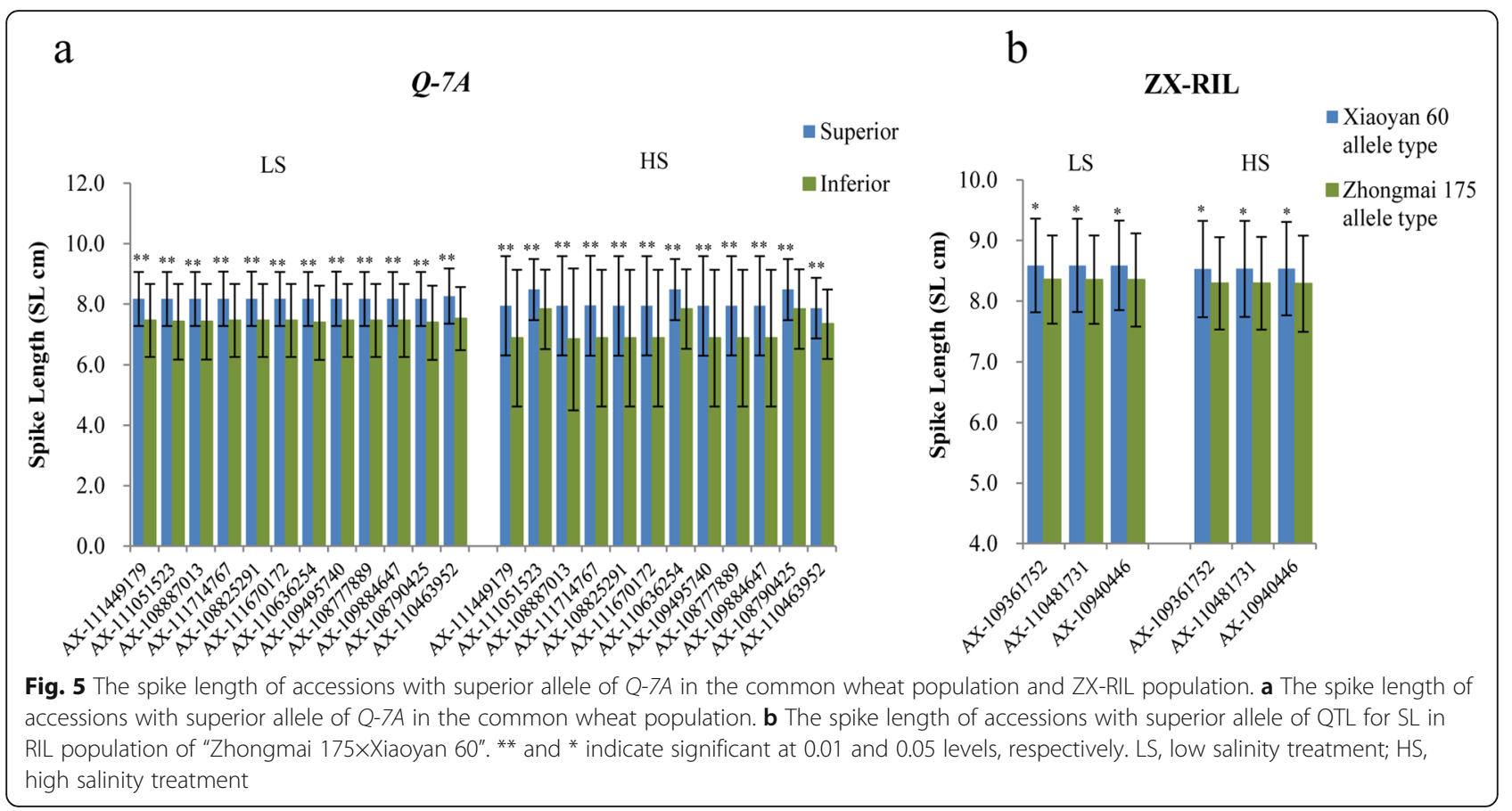

high salinity and were genotyped using Wheat660K SNP array. GWAS analysis showed that a total of 389 SNPs was significantly associated with eight traits in wheat under two different salinity conditions, and 11 loci could have key roles in affecting plant height, yield and related traits of wheat under salt stress. Four loci with high frequencies of favorable alleles were identified for YPP, SN, SL, GN and BM in position $692.16-692.39 \mathrm{Mb}$ on chromosome $5 \mathrm{~A}$ and in positions $574.06-578.35 \mathrm{Mb}$, $580.03-584.89 \mathrm{Mb}$, and $690.08-690.70 \mathrm{Mb}$ on chromosome $5 \mathrm{~B}$. For nine loci that closely linked with yield and related traits, 14 KASP markers were successfully developed and three of them were validated in a bi-parental population derived from Hanxuan 10 and Lumai 14. These findings provided useful information for wheat salt-tolerance improvement by marker assisted selection in future.

\section{Methods}

\section{Plant materials}

The plant material was a collection of 191 wheat accessions including five introduced varieties, ten landraces and 176 improved cultivars (Table S1). Except for one improved cultivar from an unknown source, these genotypes originated from Chile (1), Italy (2), Romania (1), Soviet Union (1) and Chinese provinces including Anhui (1), Beijing (17), Gansu (3), Hebei (40), Henan (30), Inner Mongolia (1), Jilin (1), Qinghai (6), Shaanxi (39), Shandong (34), Shanxi (8), Sichuan (3), Tianjin (1) and Tibet (1). Details for each accession were given in Table S1. The sampling was approved by the Institute of
Genetics and Developmental Biology, Chinese Academy of Sciences (Beijing, China). And all the plant materials were provided by the Institute of Genetics and Developmental Biology, Chinese Academy of Sciences (Beijing, China).

Significant SNPs revealed by GWAS were validated by a RIL population Zhongmai 175/Xiaoyan 60 with $350 \mathrm{~F}_{7}$ lines (ZX-RIL) and a Double Haploid population Hanxuan 10/ Lumai 14 (HL-DH) with 150 lines.

\section{Field experiments and phenotyping}

The 191 accessions were planted and harvested at Nanpi Eco-Agricultural Experimental Station, Chinese Academy of Sciences (Cangzhou, Hebei, $38^{\circ} 00^{\prime} \mathrm{N}, 116^{\circ} 40^{\prime} \mathrm{E}$, Altitude $11 \mathrm{~m}$ ) in 2014-2015, 2015-2016, and 20162017 cropping seasons. This station is located in the warm temperate semi-humid monsoon climate zone, with average annual temperature $12.3^{\circ} \mathrm{C}$ and average annual precipitation $480 \mathrm{~mm}$. The normal soil in Nanpi Eco-Agricultural Experimental Station is typical in drought and salt stress around Bohai Sea region and represents LS treatment. The salinity of normal soil in Nanpi was $0.18 \%(\mathrm{~m} / \mathrm{m})$ according to the detection values in decades. HS treatment was set in salt pools which were artificially made. The soil salinity of salt pools was guaranteed at $0.3 \%(\mathrm{~m} / \mathrm{m})$ by adding sea-salt solution with specific concentration into normal soil. The total salt content of the soil was determined by chloride-Silver nitrate titration method. Hence, two treatments, LS $(0.18 \%, \mathrm{~m} / \mathrm{m})$ and $\mathrm{HS}(0.3 \%, \mathrm{~m} / \mathrm{m})$ were set. Totally, six salinity environments were designated as 
Table 4 Haplotype analysis of the important loci

\begin{tabular}{|c|c|c|c|c|c|c|c|c|c|c|c|c|}
\hline Locus & Traits & $\begin{array}{l}\text { No. } \\
\text { of } \\
\text { SNPs }\end{array}$ & $\begin{array}{l}\text { No. of } \\
\text { haplotypes }\end{array}$ & Sequence of alleles & $\begin{array}{l}\text { Frequency } \\
\text { (\%) }\end{array}$ & Traits & $\begin{array}{l}\text { 15LS } \\
\text { Mean } \pm \\
\text { S.D }\end{array}$ & $\begin{array}{l}\text { 16LS } \\
\text { Mean } \pm \\
\text { S.D }\end{array}$ & $\begin{array}{l}\text { 17LS } \\
\text { Mean } \pm \\
\text { S.D }\end{array}$ & $\begin{array}{l}\text { 15HS } \\
\text { Mean } \pm \\
\text { S.D }\end{array}$ & $\begin{array}{l}16 \mathrm{HS} \\
\text { Mean } \pm \\
\text { S.D }\end{array}$ & $\begin{array}{l}\text { 17HS } \\
\text { Mean } \pm \\
\text { S.D }\end{array}$ \\
\hline \multirow[t]{2}{*}{$\begin{array}{l}\text { QSI- } \\
1 B\end{array}$} & SL & 11 & 2 & TCTCATCCCCT $^{* *}$ & 33.51 & $S L$ & $\begin{array}{l}9.65 \pm \\
0.99\end{array}$ & $\begin{array}{l}7.77 \pm \\
1.01\end{array}$ & $\begin{array}{l}8.54 \pm \\
0.85\end{array}$ & $\begin{array}{l}8.57 \pm \\
1.17\end{array}$ & $\begin{array}{l}7.31 \pm \\
1.24\end{array}$ & $\begin{array}{l}8.89 \pm \\
0.98\end{array}$ \\
\hline & & & & CTCTGAGATTC & 52.88 & $S L$ & $\begin{array}{l}8.95 \pm \\
1.09\end{array}$ & $\begin{array}{l}7.05 \pm \\
0.96\end{array}$ & $\begin{array}{l}7.87 \pm \\
0.67\end{array}$ & $\begin{array}{l}7.79 \pm \\
1.01\end{array}$ & $\begin{array}{l}6.71 \pm \\
1.02\end{array}$ & $\begin{array}{l}8.20 \pm \\
0.90\end{array}$ \\
\hline \multirow[t]{3}{*}{$\begin{array}{l}\text { QYpp- } \\
3 A\end{array}$} & YPP & 6 & 3 & CCAATG** & 5.24 & YPP & $\begin{array}{l}26.56 \pm \\
4.85\end{array}$ & $\begin{array}{l}22.57 \pm \\
5.17\end{array}$ & $\begin{array}{l}24.84 \pm \\
3.63\end{array}$ & $\begin{array}{l}14.36 \pm \\
1.94\end{array}$ & $\begin{array}{l}19.37 \pm \\
3.89\end{array}$ & $\begin{array}{l}23.21 \pm \\
5.17\end{array}$ \\
\hline & & & & ATAATG & 77.49 & YPP & $\begin{array}{l}19.33 \pm \\
6.49\end{array}$ & $\begin{array}{l}18.74 \pm \\
5.24\end{array}$ & $\begin{array}{l}19.25 \pm \\
4.20\end{array}$ & $\begin{array}{l}10.43 \pm \\
3.67\end{array}$ & $\begin{array}{l}12.96 \pm \\
5.45\end{array}$ & $\begin{array}{l}16.61 \pm \\
4.95\end{array}$ \\
\hline & & & & ATGGGA & 4.71 & YPP & $\begin{array}{l}17.65 \pm \\
7.75\end{array}$ & $\begin{array}{l}16.13 \pm \\
5.59\end{array}$ & $\begin{array}{l}18.31 \pm \\
4.84\end{array}$ & $\begin{array}{l}9.22 \pm \\
4.24\end{array}$ & $\begin{array}{l}10.02 \pm \\
5.51\end{array}$ & $\begin{array}{l}17.60 \pm \\
4.04\end{array}$ \\
\hline \multirow[t]{2}{*}{$\begin{array}{l}\text { QSI- } \\
3 B\end{array}$} & $S L$ & 5 & 2 & CAGTT** & 30.37 & $S L$ & $\begin{array}{l}9.38 \pm \\
1.50\end{array}$ & $\begin{array}{l}7.70 \pm \\
1.02\end{array}$ & - & $\begin{array}{l}8.36 \pm \\
1.48\end{array}$ & - & - \\
\hline & & & & TGTCA & 65.97 & $S L$ & $\begin{array}{l}8.84 \pm \\
1.77\end{array}$ & $\begin{array}{l}7.16 \pm \\
0.91\end{array}$ & - & $\begin{array}{l}7.60 \pm \\
1.75\end{array}$ & - & - \\
\hline \multirow[t]{2}{*}{$\begin{array}{l}\text { QTkW- } \\
4 A\end{array}$} & TKW & 25 & 2 & $\begin{array}{l}\text { CCGCCCGGGCGTGCGCGC } \\
\text { TGGATCC }^{* *}\end{array}$ & 8.90 & TKW & - & $\begin{array}{l}52.36 \pm \\
5.43\end{array}$ & $\begin{array}{l}46.03 \pm \\
4.75\end{array}$ & - & $\begin{array}{l}49.14 \pm \\
5.77\end{array}$ & $\begin{array}{l}40.20 \pm \\
4.80\end{array}$ \\
\hline & & & & $\begin{array}{l}\text { TIATTGATATACCTATAT } \\
\text { CCTGAGT }\end{array}$ & 83.77 & TKW & - & $\begin{array}{l}47.92 \pm \\
6.02\end{array}$ & $\begin{array}{l}40.92 \pm \\
4.79\end{array}$ & - & $\begin{array}{l}43.60 \pm \\
9.83\end{array}$ & $\begin{array}{l}37.65 \pm \\
4.99\end{array}$ \\
\hline \multirow[t]{2}{*}{$\begin{array}{l}\text { QPh- } \\
4 D\end{array}$} & $\mathrm{PH}$ & 4 & 2 & GCTG** & 68.06 & $\mathrm{PH}$ & $\begin{array}{l}78.14 \pm \\
20.67\end{array}$ & $\begin{array}{l}77.55 \pm \\
13.49\end{array}$ & $\begin{array}{l}82.70 \pm \\
14.71\end{array}$ & $\begin{array}{l}63.40 \pm \\
17.55\end{array}$ & $\begin{array}{l}58.83 \pm \\
15.80\end{array}$ & $\begin{array}{l}73.26 \pm \\
12.67\end{array}$ \\
\hline & & & & TTCA & 28.27 & $\mathrm{PH}$ & $\begin{array}{l}67.92 \pm \\
6.00\end{array}$ & $\begin{array}{l}65.98 \pm \\
5.81\end{array}$ & $\begin{array}{l}69.37 \pm \\
6.02\end{array}$ & $\begin{array}{l}57.58 \pm \\
4.86\end{array}$ & $\begin{array}{l}53.96 \pm \\
6.53\end{array}$ & $\begin{array}{l}60.63 \pm \\
6.47\end{array}$ \\
\hline \multirow[t]{4}{*}{ Q-5A2 } & $\begin{array}{l}\text { BM } \\
\text { YPP }\end{array}$ & 4 & 2 & $\mathrm{GACC}^{* *}$ & 58.64 & BM & - & - & - & $\begin{array}{l}22.84 \pm \\
6.53\end{array}$ & - & - \\
\hline & & & & AGAT & 37.17 & BM & - & - & - & $\begin{array}{l}19.93 \pm \\
8.86\end{array}$ & - & - \\
\hline & & & & $\mathrm{GACC}^{* *}$ & 58.64 & YPP & - & - & - & $\begin{array}{l}11.35 \pm \\
3.11\end{array}$ & - & - \\
\hline & & & & AGAT & 37.17 & YPP & - & - & - & $\begin{array}{l}9.73 \pm \\
4.30\end{array}$ & - & - \\
\hline \multirow[t]{6}{*}{$Q-5 B 1$} & $\begin{array}{l}\text { SL BM } \\
\text { GN } \\
\text { YPP }\end{array}$ & 4 & 2 & $\mathrm{AGCA}^{* *}$ & 88.48 & $\mathrm{BM}$ & - & - & - & $\begin{array}{l}22.46 \pm \\
8.29\end{array}$ & $\begin{array}{l}26.54 \pm \\
10.51\end{array}$ & - \\
\hline & & & & GTTG & 4.71 & BM & - & - & - & $\begin{array}{l}15.55 \pm \\
5.51\end{array}$ & $\begin{array}{l}9.04 \pm \\
6.53\end{array}$ & - \\
\hline & & & & AGCA** & 88.48 & $S L$ & - & - & - & - & $\begin{array}{l}6.94 \pm \\
1.22\end{array}$ & - \\
\hline & & & & GTTG & 4.71 & $S L$ & - & - & - & - & $\begin{array}{l}5.45 \pm \\
2.54\end{array}$ & - \\
\hline & & & & AGCA** & 88.48 & YPP & - & $\begin{array}{l}19.28 \pm \\
5.59\end{array}$ & - & $\begin{array}{l}11.11 \pm \\
3.93\end{array}$ & $\begin{array}{l}13.88 \pm \\
5.48\end{array}$ & - \\
\hline & & & & GTTG & 4.71 & YPP & - & $\begin{array}{l}15.33 \pm \\
4.65\end{array}$ & - & $\begin{array}{l}7.30 \pm \\
2.45\end{array}$ & $\begin{array}{l}4.51 \pm \\
3.67\end{array}$ & - \\
\hline \multirow[t]{2}{*}{$\begin{array}{l}\text { QSI- } \\
5 B 2\end{array}$} & $S L$ & 21 & 2 & $\begin{array}{l}\text { CTITAGCGACCGGGCGG } \\
\text { CCC }^{* *}\end{array}$ & 85.86 & $S L$ & - & - & - & - & $\begin{array}{l}6.89 \pm \\
1.35\end{array}$ & - \\
\hline & & & & $\begin{array}{l}\text { TCCCCGAGAGTAAAAAAT } \\
\text { GTA }\end{array}$ & 4.71 & SL & - & - & - & - & $\begin{array}{l}4.58 \pm \\
2.88\end{array}$ & - \\
\hline \multirow[t]{2}{*}{$Q-5 B 3$} & $\begin{array}{l}\text { SN BM } \\
\text { YPP } \\
\text { GN }\end{array}$ & 36 & 2 & $\begin{array}{l}\text { GCCCCCTGGCTCCGCCAC } \\
\text { GCCGGGGGCGTCGTGG } \\
\text { CG** }^{* *}\end{array}$ & 54.45 & $\mathrm{BM}$ & $\begin{array}{l}49.02 \pm \\
16.02\end{array}$ & - & - & $\begin{array}{l}23.90 \pm \\
8.11\end{array}$ & - & - \\
\hline & & & & $\begin{array}{l}\text { TAAGGTCAATCATATTGT } \\
\text { ATTAATAAAACTTCCATT }\end{array}$ & 12.57 & $\mathrm{BM}$ & $\begin{array}{l}35.86 \pm \\
15.96\end{array}$ & - & - & $\begin{array}{l}18.35 \pm \\
8.87\end{array}$ & - & - \\
\hline
\end{tabular}


Table 4 Haplotype analysis of the important loci (Continued)

\begin{tabular}{|c|c|c|c|c|c|c|c|c|c|c|c|c|}
\hline Locus & Traits & $\begin{array}{l}\text { No. } \\
\text { of } \\
\text { SNPs }\end{array}$ & $\begin{array}{l}\text { No. of } \\
\text { haplotypes }\end{array}$ & Sequence of alleles & $\begin{array}{l}\text { Frequency } \\
(\%)\end{array}$ & Traits & $\begin{array}{l}15 \mathrm{LS} \\
\text { Mean } \pm \\
\text { S.D }\end{array}$ & $\begin{array}{l}16 \mathrm{LS} \\
\text { Mean } \pm \\
\text { S.D }\end{array}$ & $\begin{array}{l}\text { 17LS } \\
\text { Mean } \pm \\
\text { S.D }\end{array}$ & $\begin{array}{l}15 \mathrm{HS} \\
\text { Mean } \pm \\
\text { S.D }\end{array}$ & $\begin{array}{l}\text { 16HS } \\
\text { Mean } \pm \\
\text { S.D }\end{array}$ & $\begin{array}{l}\text { 17HS } \\
\text { Mean } \pm \\
\text { S.D }\end{array}$ \\
\hline & & & & $\begin{array}{l}\text { GCCCCCTGGCTCCGCCAC } \\
\text { GCCGGGGGCGTCGTGG } \\
\text { CG }^{* *}\end{array}$ & 54.45 & GN & $\begin{array}{l}627.45 \pm \\
194.97\end{array}$ & $\begin{array}{l}415.44 \pm \\
107.02\end{array}$ & - & $\begin{array}{l}301.59 \pm \\
113.55\end{array}$ & $\begin{array}{l}310.88 \pm \\
116.97\end{array}$ & - \\
\hline & & & & $\begin{array}{l}\text { TAAGGTCAATCATATTGT } \\
\text { ATTAATAAAACTTCCATT }\end{array}$ & 12.57 & GN & $\begin{array}{l}448.46 \pm \\
203.83\end{array}$ & $\begin{array}{l}361.03 \pm \\
132.06\end{array}$ & - & $\begin{array}{l}221.08 \pm \\
105.19\end{array}$ & $\begin{array}{l}255.05 \pm \\
144.92\end{array}$ & - \\
\hline & & & & $\begin{array}{l}\text { GCCCCCTGGCTCCGCCAC } \\
\text { GCCGGGGGCGTCGTGG } \\
\text { CG** }^{* *}\end{array}$ & 54.45 & SN & $\begin{array}{l}15.43 \pm \\
4.51\end{array}$ & $\begin{array}{l}10.69 \pm \\
2.34\end{array}$ & - & $\begin{array}{l}6.75 \pm \\
2.32\end{array}$ & - & - \\
\hline & & & & $\begin{array}{l}\text { TAAGGTCAATCATATTGT } \\
\text { ATTAATAAAACTTCCATT }\end{array}$ & 12.57 & SN & $\begin{array}{l}11.31 \pm \\
5.38\end{array}$ & $\begin{array}{l}9.43 \pm \\
3.04\end{array}$ & - & $\begin{array}{l}5.33 \pm \\
2.46\end{array}$ & - & - \\
\hline & & & & $\begin{array}{l}\text { GCCCCCTGGCTCCGCCAC } \\
\text { GCCGGGGGCGTCGTGG } \\
\text { CG }^{* *}\end{array}$ & 54.45 & YPP & $\begin{array}{l}21.65 \pm \\
6.80\end{array}$ & - & - & $\begin{array}{l}11.78 \pm \\
3.73\end{array}$ & - & - \\
\hline & & & & $\begin{array}{l}\text { TAAGGTCAATCATATTGT } \\
\text { ATTAATAAAACTTCCATT }\end{array}$ & 12.57 & YPP & $\begin{array}{l}16.43 \pm \\
7.39\end{array}$ & - & - & $\begin{array}{l}9.17 \pm \\
4.39\end{array}$ & - & - \\
\hline \multirow[t]{4}{*}{ Q-7A } & SL YPP & 12 & 2 & CGTTACGACCCT** & 90.58 & $S L$ & - & $\begin{array}{l}7.39 \pm \\
1.02\end{array}$ & $\begin{array}{l}8.18 \pm \\
0.90\end{array}$ & - & - & $\begin{array}{l}8.49 \pm \\
1.12\end{array}$ \\
\hline & & & & TTACGTAGATAA & 5.24 & $S L$ & - & $\begin{array}{l}6.77 \pm \\
0.87\end{array}$ & $\begin{array}{l}7.28 \pm \\
1.31\end{array}$ & - & - & $\begin{array}{l}7.76 \pm \\
1.42\end{array}$ \\
\hline & & & & CGTTACGACCCT ${ }^{* *}$ & 90.58 & YPP & $\begin{array}{l}23.71 \pm \\
6.62\end{array}$ & - & - & - & - & - \\
\hline & & & & TTACGTAGATAA & 5.24 & YPP & $\begin{array}{l}19.08 \pm \\
8.93\end{array}$ & - & - & - & - & - \\
\hline
\end{tabular}

$P H$ plant height, $S N$ spike number, $S L$ spike length, GN grain number, $T K W$ thousand kernels weight, $Y P P$ yield per plot, $B M$ biological mass, $L S$ low salinity treatment, $H S$ high salinity treatment, $S$. D standard deviation

** represents the favorable haplotype

"--" represents no significantly difference between haplotypes

15LS, 15HS, 16LS, 16HS, 17LS and 17HS. Each salt pool was a cement pond of $6.6 \mathrm{~m} \times 2 \mathrm{~m} \times 1.5 \mathrm{~m}$, with waterproof cement thickness of $10 \mathrm{~cm}$ at the bottom. The bottom of the cement pond was paved with stones and river sand, and covered with non-woven fabrics. The soil evenly mixed with sea-salt solution was filled in the whole cement pond. The salt concentration of salt pool was checked from time to time, with the assurance that the salinity was maintained at $0.3 \%(\mathrm{~m} / \mathrm{m})$. The LS and HS treatments did not involve artificial irrigation during the cropping seasons. The field experiments were performed using a completely randomized design with five replications. Each block contained sixteen 200-cm-long rows with $10 \mathrm{~cm}$ between neighboring plants and $23 \mathrm{~cm}$ between neighboring rows. Hole sowing method was used and three sprouted seeds of any accession were sown in each plot. The three plants in one hole were harvest together and eight phenotypic traits at adult stage were investigated, including plant height $(\mathrm{PH})$, spike number (SN), spike length (SL), kernels per spike (KPS), grain number (GN), thousand kernel weight (TKW), yield per plot (YPP) and biological mass (BM). Measurement methods for each trait were as follows: $\mathrm{PH}$ was the distance between the stem base and the top of the main spike excluding awns, SN was the number of spikes per plot, SL was the length of the main spike per plot, KPS was the kernel number of main spike per plot, GN was the number of grains per plot, TKW was the calculated by $(\mathrm{YPP} / \mathrm{GN}) \times 1000$, YPP was the weight of grains per plot, BM was the aboveground weight per plot. The relative value of high salinity/low salinity (HS/ LS) for each trait was also calculated and used for genome-wide association analysis.

The phenotypes of ZX-RIL and HL-DH were used to validate significant SNPs detected by GWAS. These two populations were planted and harvested under LS and HS conditions at Nanpi Eco-Agricultural Experimental Station in 2016-2017 (ZX-RIL) and 2017-2018 (ZX-RIL and HL-DH). Three repeated rows and ten replicated individuals were set for low and high salinity treatment, respectively. Seeds were sowed with row space $20 \mathrm{~cm}$ and plant space $10 \mathrm{~cm}$. Phenotypic traits were investigated as mentioned above.

\section{Genotyping}

Genomic DNA was extracted from fresh leaves collected from the 191 accessions using a CTAB method [82] . Then, DNA samples were sent to the Capital $\mathrm{Bio}^{\oplus}$ genotyping facility (Beijing, China) for SNP genotyping with the Axiom Wheat660K Genotyping Array (https://wheat. 
a

Protortion of wheat accession contained different number of favorable haplotype for traits and locus

SL

OSI- $1 B+O S L-3 B+0-5$

$Q-5 A 2+Q-7 A$

$1.05 \% 6.28 \%$

$55.50 \%$

$25.65 \%$

$11.52 \%$

YPP

$Q Y p p-3 A+Q-5 A 2+Q-7 A$

$4.71 \%$

$39.27 \%$

$52.88 \%$

co-location locus

$Q-5 A 2+Q-5 B 1+Q S l-5 B 2+Q-5 B 3$

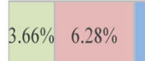

$20.42 \%$

$38.22 \%$

$31.41 \%$

घero favorable haplotype $\llbracket$ one favorable haplotype $\llbracket$ two favorable haplotypes $\square$ three favorable haplotypes $\llbracket$ four favorable haplotypes

b

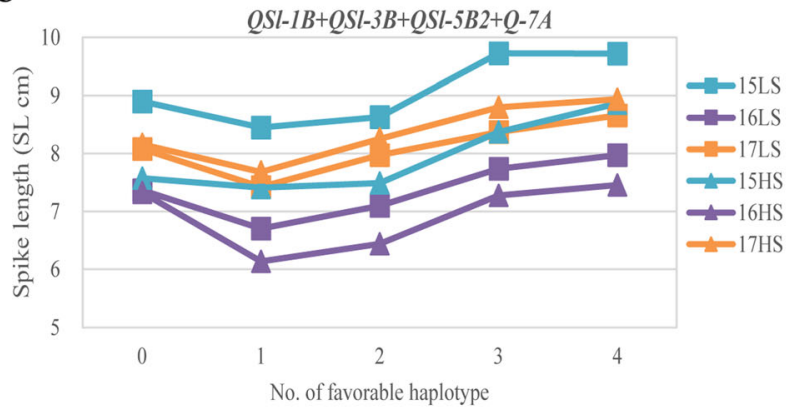

d

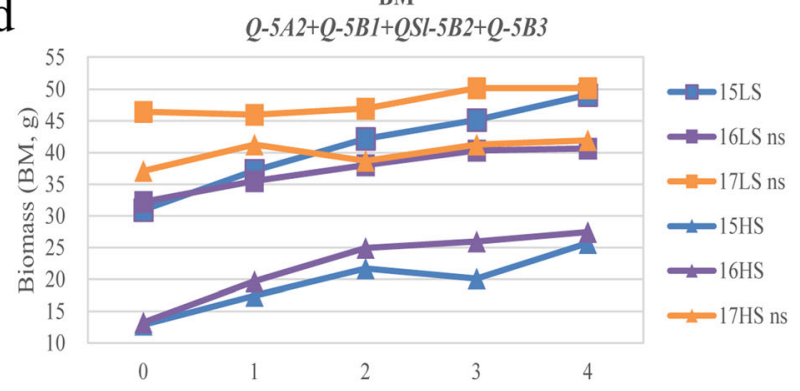

c

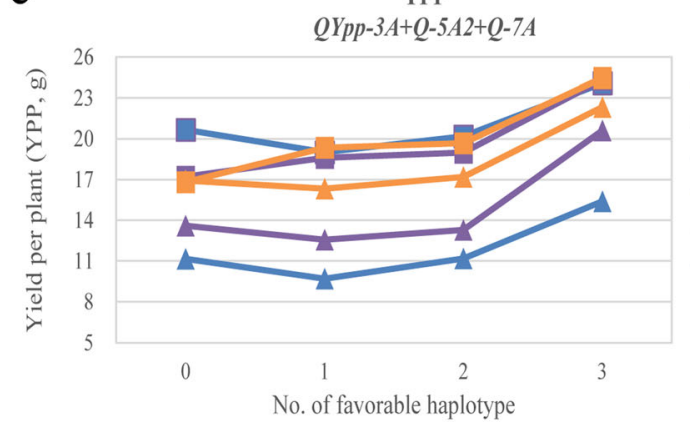

GN

e

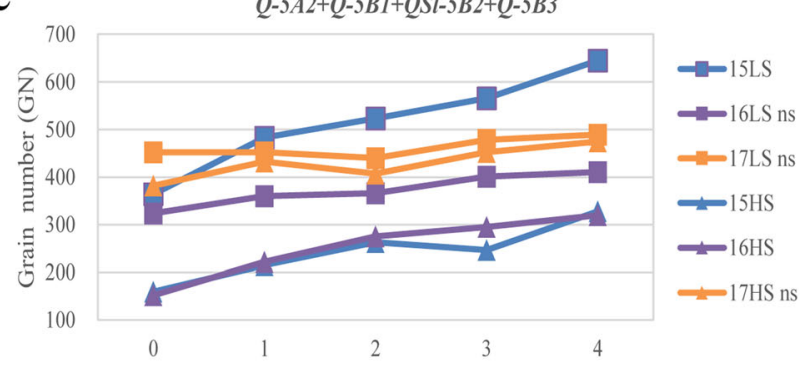

g

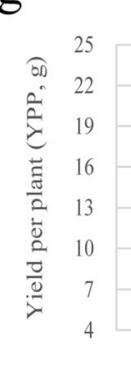

YPP

$Q-5 A 2+Q-5 B 1+Q S I-5 B 2+Q-5 B 3$

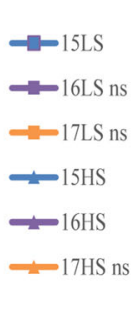

$Q-5 A 2+Q-5 B 1+Q S 1-5 B 2+Q-5 B 3$

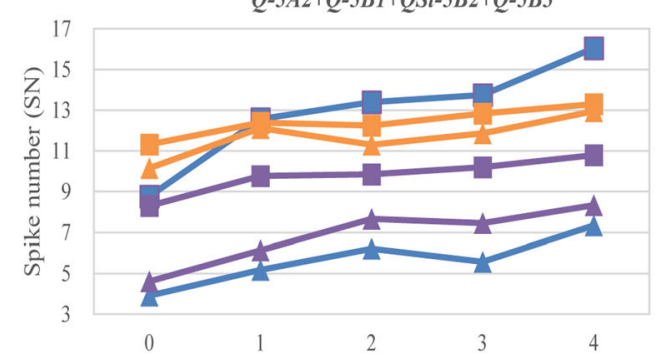

Fig. 6 The proportions and phenotype values of wheat accessions contained different number of favorable haplotypes for traits and loci. a The proportion of wheat accessions contained different number of favorable haplotype for spike length (SL), yield per plot (YPP) and the co-location loci on the group-5 chromosomes. The percentage represents the proportion of wheat accessions. $\mathbf{b}$ Spike length comparison of wheat accessions contained different number of favorable haplotypes of loci associated with SL. c Yield comparison of wheat accessions contained different number of favorable haplotypes of loci associated with YPP. $\mathbf{b}-\mathbf{g}$ Phenotype comparison of wheat accessions contained different number of favorable haplotypes of co-location loci on the group- 5 chromosomes. LS, low salinity treatment; HS, high salinity treatment. ns represents no significantly difference 
pw.usda.gov/ggpages/topics/Wheat660_SNP_array_ developed_by_CAAS.pdf) according to the manufacturer's instructions (Axiom 2.0 Assay Manual Workflow User Guide Rev3). Markers were removed from the dataset for SNP call rate less than $80 \%$ and minor allele frequencies less than 0.05 . This quality preprocessing of genotyping data was completed using PLINK software (http://pngu.mgh.harvard.edu/purcell/plink/) [83].

\section{Statistical analysis \\ Phenotypes}

Phenotypic data were analyzed with SAS v.9.2 software (SAS Institute Inc., Cary, NC). Analyses of variance (ANOVA), co-efficient of correlation and repeatability were calculated for all traits. Heritability estimates were calculated using the formula: $H^{2}=\sigma_{\mathrm{g}}^{2} /\left(\sigma_{\mathrm{g}}^{2}+\sigma_{\mathrm{ge}}^{2} / r+\right.$ $\sigma_{\varepsilon}^{2} / r e$ ), where $\sigma_{\mathrm{g}}^{2}$, $\sigma_{\mathrm{ge}}^{2}$ and $\sigma_{\varepsilon}^{2}$ were estimates of genotype, genotype $\times$ environment interaction and residual error variances, respectively, and e and $r$ represented the number of environment and replicates, respectively.

\section{Population structure and kinship analysis}

Linkage disequilibrium (LD) among markers was investigated using TASSEL 5.0 with the markers whose positions were known [84]. A distance matrix was established by the SNPs shared by all the accessions using PLINK [83]. Based on this distance matrix, a neighbor-joining tree was constructed using PHYLIP software. Kinship matrixes (the $\mathrm{K}$ model) were established to infer relationship among accessions using TASSEL 5.0 [84]. Population structure (the Q matrix) was calculated using the Bayesian clustering program Structure V2.3.4 [85]. The structure program was run ten times for each subpopulation $(\mathrm{k})$ value, ranging from 1 to 15 , with a burn-in period at 100,000 iteration and a run of 500,000 replication of Markov Chain Monte Carlo (MCMC) after burn in [85]. The subpopulation number was estimated using the $\Delta \mathrm{K}$ method [86]. Meanwhile, Principal Component Analysis was performed to infer population stratification via TASSEL 5.0 [84].

\section{Genome-wide association analysis}

Associations between SNPs and phenotypic variations were tested with mixed linear model (MLM) by TASSEL 5.0 [84]. And two factors including population structure (Q matrix) and relationship kinship (K model) were used as confounding factors $[87,88]$. The first five principal components of SNPs were leaded in the GWAS model. A GAPIT package [89] in R software using MLM was conducted to check the consistency and accuracy of the results from TASSEL.
Development of KASP markers for association SNPs

The Kompetitive Allele Specifc Polymerase Chain Reaction (KASP) (LGC Genomics LLC, Beverly, MA, USA) markers were developed to detect and distinguish alleles of key SNPs for the important loci. One or two representative SNPs were selected for each locus, excepting for the loci of PH. A total of 14 SNPs were converted to KASP markers for nine loci. Sequences from the Wheat660K array flanking the SNP were used for KASP primer design by Primer Premier 5 software. KASP reactions and detection of the fluorescence signal were performed according to the KASP manual by Capital $\mathrm{Bio}^{\circ}$ genotyping facility (Beijing, China).

\section{Supplementary Information}

The online version contains supplementary material available at https://doi. org/10.1186/s12870-020-02799-1.

Additional file 1: Table S1. Name and origin of the 191 common wheat accessions used in this study.

Additional file 2: Table S2. Correlation analysis of the field experiments from 2015 to 2017 under low and high salinity treatments. PH, plant height; SN, spike number; SL, spike length; KPS, kernels per spike; GN, grain number; TKW, thousand kernels weight; YPP, yield per plot; BM, biological mass. ${ }^{*}$ represented significant difference determined at $p<0.01$. LS, low salinity treatment; HS, high salinity treatment.

Additional file 3: Table S3. Genetic diversity in each chromosome was calculated according to genotypic data of Wheat660K SNPs chip in the 191 wheat accessions under low and high salinity treatments.

Additional file 4: Table S4. GWAS results of the eight agronomic traits among the 191 common wheat accessions under low and high salinity treatments. PH, plant height; SN, spike number; SL, spike length; KPS, kernels per spike; GN, grain number; TKW, thousand kernels weight; YPP, yield per plot; BM, biological mass. LS, low salinity treatment; HS, high salinity treatment; UN, unknown.

Additional file 5: Table S5. Candidate SNPS revealed by GWAS in 191 common wheat accessions under low and high salinity treatments. $\mathrm{PH}$, plant height; SN, spike number; SL, spike length; KPS, kernels per spike; GN, grain number; TKW, thousand kernels weight; YPP, yield per plot; BM, biological mass. LS, low salinity treatment; HS, high salinity treatment.

Additional file 6: Table S6. Favored alleles and genetic effects of 11 loci associated with traits under low and high salinity treatments. $\mathrm{PH}$, plant height; SN, spike number; SL, spike length; KPS, kernels per spike; GN, grain number; TKW, thousand kernels weight; YPP, yield per plot; BM, biological mass. LS, low salinity treatment; HS, high salinity treatment. "ns" represents no calculation for no significantly difference of traits between alleles.

Additional file 7: Table S7. SNPs loci significantly associated with yieldrelated traits identified in the present and previous studies. $\mathrm{PH}$, plant height; SN, spike number; SL, spike length; KPS, kernels per spike; GN, grain number; TKW, thousand kernels weight; YPP, yield per plot; BM, biological mass.

Additional file 8: Table S8. The information of the 14 KASP markers developed for nine loci. PH, plant height; SN, spike number; SL, spike length; KPS, kernels per spike; GN, grain number; TKW, thousand kernels weight; YPP, yield per plot; BM, biological mass.

Additional file 9: Figure S1. The average number of favorable alleles of common wheat accessions. (a) The average number of favorable alleles of common wheat accessions from different types. (b) The average number of favorable alleles of common wheat accessions from different regions. 
Additional file 10: Figure S2. Mean difference in different traits between HX and LM alleles in DH population of "Hanxuan 10xLumai 14", where HX indicated the "Huanxuan 10" allele and LM indicated "Lumai $14^{\prime \prime}$ allele (** indicates significant at 0.01 level).

Additional file 11: Figure S3. QTL position on chromosome 5B for spike length (SL) in the common wheat population and ZX-RIL population. (a) Chromosome location of Q-5B1 in the 191 common wheat accessions. (b) QTL position for SPS in RIL population of "Zhongmai $175 \times X i a o y a n$ 60". (c) LD plot of the QSI-5B1 in the 191 common wheat accessions and the QTL for SPS in RIL population of "Zhongmai $175 \times$ Xiaoyan 60".

Additional file 12: Figure S4. The proportion of different haplotypes for each locus. The percentage represented the proportion of haplotype in the 191 common wheat accessions.

Additional file 13: Figure S5. Haplotype analysis of the important loci. $\mathrm{PH}$, plant height; SN, spike number; SL, spike length; GN, grain number; TKW, thousand kernels weight; YPP, yield per plot; BM, biological mass. LS, low salinity treatment; HS, high salinity treatment.

Additional file 14: Figure S6. Scatter plots of the 14 KASP markers for nine key loci identified in the present study. Red dots indicate the accessions had the FAM-type allele; blue dots indicate the accessions had the HEX-type allele.

\section{Abbreviations}

BM: Biological mass; GN: Grain number; GWAS: Genome-wide association studies; KPS: Kernels per spike; PH: Plant height; QTL: Quantitative trait loci; SN: Spike number; SNP: Single nucleotide polymorphism; SL: Spike length; TKW: Thousand kernels weight; YPP: Yield per plot

\section{Acknowledgements}

We are grateful to Prof. Ruilian Jing and Prof. Xueyong Zhang from the Institute of Crop Science, Chinese Academy of Agricultural Sciences, Beijing, China, for providing $\mathrm{HL}-\mathrm{DH}$ population and some wheat accessions.

\section{Authors' contributions}

ZSL and QZ conceived the research; QZ, QLL, PH and WT designed the experiment; QLL developed the ZX-RIL population; QZ, PH and QLL performed phenotype of the ZX-RIL population under two environments; QZ, WT and PH performed phenotype of the 191 wheat accessions under six environments; PH performed GWAS analysis and wrote the manuscript; QZ also put forward many constructive suggestions and revised the manuscript. BL and HWL provided a lot of help in the materials preparation and experiments performance. All authors read and approved the final manuscript.

\section{Funding}

This study was supported by the Strategic Priority Research Program of the Chinese Academy of Sciences (No. XDA24030302 \& No. XDA08030105). The supporter provided financial help for experiment design, data collection, data analysis and manuscript writing

\section{Availability of data and materials}

The data sets supporting the results of this study are included within the article and its additional files. The experiment data reported in this study have been deposited in the Genomic Expression Archive (GEA) in Bioinformation and DDBJ Center under accession number E-GEAD-406 at https://ddbj.nig.ac.jp/gea/reviewer, the access key is "bDhkCrXEb17jzYrxoMpt". The genotype data have been also deposited in the Genome Variation Map (GVM) in Big Data Center, Beijing Institute of Genomics (BIG), Chinese Academy of Science, under accession numbers GVM000089 at http://bigd.big.ac.cn/gvm/getProjectDetail?project=GVM000089.

\section{Ethics approval and consent to participate}

Not applicable

\section{Consent for publication}

Not applicable

\section{Competing interests}

The authors declare that they have no competing interests.
Received: 8 April 2020 Accepted: 16 December 2020

Published online: 07 January 2021

\section{References}

1. Munns R, Tester M. Mechanisms of salinity tolerance. Annu Rev Plant Biol. 2008:59:651-81.

2. Wang M, Xia G. The landscape of molecular mechanisms for salt tolerance in wheat. Crop J. 2018;6(1):42-7.

3. Wang D, Zhang K, Dong L, Dong Z, Li Y, Hussain A, Zhai H. Molecular genetic and genomic analysis of wheat milling and end-use traits in China: Progress and perspectives. Crop J. 2018;6(1):68-81.

4. Yamaguchi T, Blumwald E. Developing salt-tolerant crop plants: challenges and opportunities. Trends Plant Sci. 2005;10(12):615-20.

5. Jia M, Guan J, Zhai Z, Geng S, Zhang X, Mao L, Li A. Wheat functional genomics in the era of next generation sequencing: an update. Crop J. 2018;6(1):7-14.

6. Rasheed A, Hao Y, Xia X, Khan A, Xu Y, Varshney RK, He Z. Crop breeding chips and genotyping platforms: Progress, challenges, and perspectives. Mol Plant. 2017:10(8):1047-64.

7. Abberton M, Batley J, Bentley A, Bryant J, Cai H, Cockram J, de Oliveira AC, Cseke $L$, Dempewolf H, De Pace C, et al. Global agricultural intensification during climate change: a role for genomics. Plant Biotechnol J. 2016;14(4): 1095-8.

8. Munns R, James RA, Lauchli A. Approaches to increasing the salt tolerance of wheat and other cereals. J Exp Bot. 2006;57(5):1025-43.

9. Munns R, Gilliham M. Salinity tolerance of crops - what is the cost? New Phytol. 2015;208(3):668-73

10. Wang M, Wang $S$, Xia G. From genome to gene: a new epoch for wheat research? Trends Plant Sci. 2015;20(6):380-7.

11. Cui F, Zhang $N$, Fan $X L$, Zhang W, Zhao CH, Yang $L$, Pan $R Q$, Chen $M$, Han J, Zhao XQ, et al. Utilization of a Wheat660K SNP array-derived high-density genetic map for high-resolution mapping of a major QTL for kernel number. Sci Rep. 2017;7(1):3788.

12. International Wheat Genome Sequencing Consortium (IWGSC). Shifting the limits in wheat research and breeding using a fully annotated reference genome. Science. 2018;361:661.

13. Wu QH, Chen YX, Zhou SH, Fu L, Chen JJ, Xiao Y, Zhang D, Ouyang SH, Zhao XJ, Cui Y, et al. High-density genetic linkage map construction and QTL mapping of grain shape and size in the wheat population Yanda1817 $x$ Beinong6. PLoS One. 2015;10(2):e0118144.

14. Ma F, Xu Y, Ma Z, Li L, An D. Genome-wide association and validation of key loci for yield-related traits in wheat founder parent Xiaoyan 6. Mol Breed. 2018;38(7).

15. Winfield MO, Allen AM, Burridge AJ, Barker GL, Benbow HR, Wilkinson PA, Coghill J, Waterfall C, Davassi A, Scopes G, et al. High-density SNP genotyping array for hexaploid wheat and its secondary and tertiary gene pool. Plant Biotechnol J. 2016;14(5):1195-206.

16. Li H, Wang Q, Xu L, Mu J, Wu J, Zeng Q, Yu S, Huang L, Han D, Kang Z. Rapid identification of a major effect QTL conferring adult plant resistance to stripe rust in wheat cultivar Yaco"S". Euphytica. 2017;213(6).

17. Tian X, Wen W, Xie L, Fu L, Xu D, Fu C, Wang D, Chen X, Xia X, Chen Q, et al. Molecular mapping of reduced plant height gene Rht24 in bread wheat. Front Plant Sci. 2017:8:1379.

18. Zhu C, Gore M, Buckler ES, Yu J. Status and prospects of association mapping in plants. Plant Genome. 2008;1(1):5-20.

19. Wang R, Chen J, Anderson JA, Zhang J, Zhao W, Wheeler J, Klassen N, See DR, Dong Y. Genome-wide association mapping of Fusarium head blight resistance in spring wheat lines developed in the Pacific northwest and CIMMYT. Phytopathology. 2017;107(12):1486-95.

20. Oyiga BC, Sharma RC, Baum M, Ogbonnaya FC, Léon J, Ballvora A. Allelic variations and differential expressions detected at quantitative trait loci for salt stress tolerance in wheat. Plant Cell Environ. 2018;41(5):919-35.

21. Riaz A, Athiyannan N, Periyannan SK, Afanasenko O, Mitrofanova OP, Platz GJ, Aitken EAB, Snowdon RJ, Lagudah ES, Hickey LT, et al. Unlocking new alleles for leaf rust resistance in the Vavilov wheat collection. Theor Appl Genet. 2018;131(1):127-44.

22. Mwadzingeni $L$, Shimelis $H$, Rees DJ, Tsilo TJ. Genome-wide association analysis of agronomic traits in wheat under drought-stressed and nonstressed conditions. PLoS One. 2017;12(2):e0171692. 
23. Hussain B, Lucas SJ, Ozturk L, Budak H. Mapping QTLs conferring salt tolerance and micronutrient concentrations at seedling stagein wheat. Sci Rep. 2017;7(1):15662.

24. Nei MCR. Estimation of fixation indices and gene diversities. Ann Hum Genet. 1983;47(3):253-9.

25. Kumar S, Beena AS, Awana M, Singh A. Physiological, biochemical, epigenetic and molecular analyses of wheat (Triticum aestivum) genotypes with contrasting salt tolerance. Front Plant Sci. 2017:8:1151.

26. Azadi A, Mardi M, Hervan EM, Mohammadi SA, Moradi F, Tabatabaee MT, Pirseyedi SM, Ebrahimi M, Fayaz F, Kazemi M, et al. QTL mapping of yield and yield components under normal and salt-stress conditions in bread wheat (Triticum aestivum L.). Plant Mol Biol Report. 2014;33(1):102-20.

27. Gao F, Wen W, Liu J, Rasheed A, Yin G, Xia X, Wu X, He Z. Genome-wide linkage mapping of QTL for yield components, plant height and yieldrelated physiological traits in the Chinese wheat cross Zhou 8425B/Chinese spring. Front Plant Sci. 2015;6:1099.

28. Sukumaran S, Dreisigacker S, Lopes M, Chavez P, Reynolds MP. Genomewide association study for grain yield and related traits in an elite spring wheat population grown in temperate irrigated environments. Theor Appl Genet. 2015;128(2):353-63.

29. Chen H, Semagn K, labal M, Moakhar NP, Haile T, N'Diaye A, Yang R-C, Hucl P, Pozniak C, Spaner D. Genome-wide association mapping of genomic regions associated with phenotypic traits in Canadian western spring wheat. Mol Breed. 2017;37(11).

30. Cui F, Li J, Ding A, Zhao C, Wang L, Wang X, Li S, Bao Y, Li X, Feng D, et al. Conditional QTL mapping for plant height with respect to the length of the spike and internode in two mapping populations of wheat. Theor Appl Genet. 2011;122(8):1517-36.

31. Liu Y, Lin Y, Gao S, Li Z, Ma J, Deng M, Chen G, Wei Y, Zheng Y. A genomewide association study of 23 agronomic traits in Chinese wheat landraces. Plant J. 2017;91(5):861-73.

32. Zhang N, Fan X, Cui F, Zhao C, Zhang W, Zhao X, Yang L, Pan R, Chen M, Han J, et al. Characterization of the temporal and spatial expression of wheat (Triticum aestivum L.) plant height at the QTL level and their influence on yield-related traits. Theor Appl Genet. 2017;130(6):1235-52.

33. Law CNWA, Giorgi B. The genetic control of earemergence time by chromosomes 5A and 5D of wheat. Heredity. 1975;36:49-58.

34. Chen S, Gao R, Wang H, Wen M, Xiao J, Bian N, Zhang R, Hu W, Cheng S, Bie $T$, et al. Characterization of a novel reduced height gene (Rht23) regulating panicle morphology and plant architecture in bread wheat. Euphytica. 2014;203(3):583-94.

35. Lu Y, Xing L, Xing S, Hu P, Cui C, Zhang M, Xiao J, Wang H, Zhang R, Wang $X$ et al. Characterization of a putative new semi-dominant reduced height gene, Rht_NM9, in wheat (Triticum aestivum L.). J Genet Genomics. 2015;42(12):685-98.

36. Peng ZS, Li X, Yang ZJ, Liao ML. A new reduced height gene found in the tetraploid semi-dwarf wheat landrace Aiganfanmai. Genet Mol Res. 2011; 10(4):2349-57.

37. Ellis H, Spielmeyer W, Gale R, Rebetzke J, Richards A. "Perfect" markers for the Rht-B1b and Rht-D1b dwarfing genes in wheat. Theor Appl Genet. 2002; 105(6-7):1038-42.

38. Li XPLS, Liu YP, Gale MD, Worland TJ. Effects of different Rht-B1b, Rht-D1b and Rht-BlC dwarfing genes on agronomic characteristics in wheat. Cereal Res Commun. 2006;34:919-24.

39. Quarrie SA, Steed A, Calestani C, Semikhodskii A, Lebreton C, Chinoy C, Steele N, Pljevljakusic D, Waterman E, Weyen J, et al. A high-density genetic map of hexaploid wheat (Triticum aestivum L.) from the cross Chinese spring $\times$ SQ1 and its use to compare QTLs for grain yield across a range of environments. Theor Appl Genet. 2005;110(5):865-80

40. DAK S. Relationship between grain yield and some agronomic characters in durum wheat under cold dryland conditions of Iran. Pak J Biol Sci. 2005;8:959-62.

41. Zarei LCKFE. Evaluation of grain yield and some agronomic characters in durun wheat under rainded conditions. Aust J Crop Sci. 2013;7(5):609.

42. Wang Z, Wu X, Ren Q, Chang X, Li R, Jing R. QTL mapping for developmental behavior of plant height in wheat (Triticum aestivum L.). Euphytica. 2010;174(3):447-58.

43. Wu X, Wang Z, Chang X, Jing R. Genetic dissection of the developmental behaviours of plant height in wheat under diverse water regimes. J Exp Bot. 2010;61(11):2923-37.

44. Díaz De León JL, Escoppinichi R, Geraldo N, Castellanos T, Mujeeb-Kazi A, Röder MS. Quantitative trait loci associated with salinity tolerance in field grown bread wheat. Euphytica. 2011;181(3):371-83.
45. Guo JLC, Zhai SHN, Li HSH, Liu AF, Cheng DG, Han R, Liu JJ, Kong LR, Zheng $\mathrm{ZH}$, Song JM. Molecular and physical mapping of powdery mildew resistance genes and QTLs in wheat: a review. Agric Sci Technol. 2017;18(6): 965-70.

46. Zheng ZHMJ, Stiller J, Zhao Q, Feng Q, Choulet F, Feuillet C, Zheng YL, Wei YM, Han B, Yan GJ, Manners JM, Liu CHJ. Fine mapping of a large-effect QTL conferring Fusarium crown rot resistance on the long arm of chromosome 3B in hexaploid wheat. BMC Genomics. 2015;16:850.

47. Min HJ, Jung YJ, Kang BG, Kim WT. CaPUB1, a hot pepper U-box E3 ubiquitin ligase, confers enhanced cold stress tolerance and decreased drought stress tolerance in transgenic rice (Oryza sativa L.). Mol Cell. 2016; 39(3):250-7.

48. Jiang $Y$, Jiang $Q$, Hao C, Hou J, Wang L, Zhang H, Zhang S, Chen X, Zhang $X$. A yield-associated gene $T a C W I$, in wheat: its function, selection and evolution in global breeding revealed by haplotype analysis. Theor App Genet. 2015;128(1):131-43.

49. Sui NTS, Wang W, Wang M, Fan H. Overexpression of glycerol-3-phosphate acyltransferase from Suaeda salsa improves salt tolerance in Arabidopsis. Front Plant Sci. 2017;8:1337.

50. Liu MZMB, Henry JS. Efficient planar heterojunction perovskite solar cells by vapour deposition. Nature. 2013;501:395-8.

51. Payá-Milans MA-MJ, Balbuena TS, Haslam RP, Gidda SK, Pérez-Hormaeche. Sunflower HaGPAT9-1 is the predominant GPAT during seed development. Plant Sci. 2016;253:42-52.

52. Ariizumi TKS, Inatsugi R, Nishida I, Murata N, Toriyama K. An increase in unsaturation of fatty acids in phosphatidyl-glycerol from leaves improves the rates of photosynthesis and growth at low temperatures in transgenic rice seedlings. Plant Cell Physiol. 2003;43:751-8.

53. Liu J, Xu Z, Fan X, Zhou Q, Cao J, Wang F, Ji G, Yang L, Feng B, Wang T. A genome-wide association study of wheat spike related traits in China. Front Plant Sci. 2018;9:1584.

54. Sun PYZW, Wang YH, He Q, Shu F, Liu H, Wang J, Wang JM, Yuan LP, Deng HF. OsGRF4 controls grain shape, panicle length and seed shattering in rice. $J$ Integr Plant Biol. 2016;58(10):836-47.

55. Huang XZQQ, Liu ZB, Sun HY, He SY, Luo D, Xia GM, Chu CC, Li JY, Fu XD. Natural variation at the DEP1 locus enhances grain yield in rice. Nat Genet. 2009;41:494-7.

56. Zhou YZJ, Li ZY, Yi CD, Liu J, Zhang HG, Tang SZ, Gu MH, Liang GH. Deletion in a quantitative trait gene QPE9-1 associated with panicle erectness improves plant architecture during rice domestication. Genetics. 2009;183:315-24.

57. Subramanyam S, Sardesai N, Puthoff DP, Meyer JM, Nemacheck JA, Gonzalo M, Williams CE. Expression of two wheat defense-response genes, Hfr-1 and Wci-1, under biotic and abiotic stresses. Plant Sci. 2006;170(1):90-103.

58. Singh TPSK. Association of grain yield and itscomponents in segregating populations of green gram. Indian J Genet. 1973;33:112-7.

59. Genc $Y$, Oldach $K$, Verbyla AP, Lott G, Hassan M, Tester M, Wallwork H, McDonald GK. Sodium exclusion QTL associated with improved seedling growth in bread wheat under salinity stress. Theor Appl Genet. 2010;121(5): 877-94

60. Ma L, Zhou E, Huo N, Zhou R, Wang G, Jia J. Genetic analysis of salt tolerance in a recombinant inbred population of wheat (Triticum aestivum $L$. ). Euphytica. 2006;153(1-2):109-17.

61. Masoudi B, Mardi M, Hervan EM, Bihamta MR, Naghavi MR, Nakhoda B, Amini A. QTL mapping of salt tolerance traits with different effects at the seedling stage of bread wheat. Plant Mol Biol Report. 2015;33(6):1790-803.

62. Narjesi V, Mardi M, Hervan EM, Azadi A, Naghavi MR, Ebrahimi M, Zali AA. Analysis of quantitative trait loci (QTL) for grain yield and agronomic traits in wheat (Triticum aestivum L.) under normal and salt-stress conditions. Plant Mol Biol Report. 2015:33(6):2030-40.

63. Genc Y, Oldach K, Gogel B, Wallwork H, McDonald GK, Smith AB. Quantitative trait loci for agronomic and physiological traits for a bread wheat population grown in environments with a range of salinity levels. Mol Breed. 2013:32(1):39-59.

64. Sukumaran S, Reynolds MP, Sansaloni C. Genome-wide association analyses identify QTL hotspots for yield and component traits in durum wheat grown under yield potential, drought, and heat stress environments. Front Plant Sci. 2018:9:81.

65. Galiba GQSSJ, Morgounov A. RFLP mapping of the vernalization (Vrnl) and frost resistance ( $F r l)$ genes on chromosome 5A of wheat. Theor Appl Genet. 1995;90:1174-9. 
66. Yan L, Helguera M, Kato K, Fukuyama S, Sherman J, Dubcovsky J. Allelic variation at the $V R N-1$ promoter region in polyploid wheat. Theor Appl Genet. 2004;109(8):1677-86.

67. LA Yan L, Tranquilli G, Helguera M, Fahima T, Dubcovsky J. Positional cloning of the wheat vernalization gene VRN1. Proc Natl Acad Sci U S A. 2003;100:6263-8.

68. Li Faji WW, Zhonghu $H$, Jindong $L$, Hui J, Shuanghe $C$, Hongwei $G$, Jun $Y$, Pingzhi Z, Yingxiu W, Xianchun X. Genome-wide linkage mapping of yieldrelated traits in three Chinese bread wheat populations using high-density SNP markers. Theor Appl Genet. 2018;131(9):1903-24.

69. Xu Y, Zheng X, Song Y, Zhu L, Yu Z, Gan L, Zhou S, Liu H, Wen F, Zhu C. NtLTP4, a lipid transfer protein that enhances salt and drought stresses tolerance in Nicotiana tabacum. Sci Rep. 2018;8(1):8873.

70. Kirubakaran SI, Begum SM, Ulaganathan K, Sakthivel N. Characterization of a new antifungal lipid transfer protein from wheat. Plant Physiol Biochem. 2008;46(10):918-27.

71. Wang F, Wang Z, Zhu C. Heteroexpression of the wheat phytochelatin synthase gene (TaPCS1) in rice enhances cadmium sensitivity. Acta Biochim Biophys Sin. 2012;44(10):886-93.

72. Al-Mashhadani Ibrahim HI. Estimation of salt tolerance degree in some selected wheat genotypes by using detection of salt tolerant gene (TaSTK) and its expression under salinity conditions. Int J Appl Agric Sci. 2015;1(2):31.

73. Ge RCCG, Zhao BC, Shen YZ, Huang ZJ. Cloning and functional characterization of a wheat serine/threonine kinase gene (TASTK) related to salt-resistance. Plant Sci. 2012;173:55-60.

74. Arora R, Agarwal P, Ray S, Singh AK, Singh VP, Tyagi AK, Kapoor S. MADSbox gene family in rice: genome-wide identification, organization and expression profiling during reproductive development and stress. BMC Genomics. 2007:8:242.

75. Ma J, Yang Y, Luo W, Yang C, Ding P, Liu Y, Qiao L, Chang Z, Geng H, Wang $P$, et al. Genome-wide identification and analysis of the MADS-box gene family in bread wheat (Triticum aestivum L.). PLoS One. 2017;12(7):e0181443.

76. Lindsay MP, Lagudah ES, Hare RA, Munns R. A locus for sodium exclusion (Nax1), a trait for salt tolerance, mapped in durum wheat. Funct Plant Biol. 2004:31(11):1105.

77. Byrt CSPJ, Spielmeyer W, James RA, Lagudah ES, Dennis ES, Tester M, Munns R. HKT1;5-like cation transporters linked to $\mathrm{Na}+$ exclusion loci in wheat, Nax2 and Kna1. Plant Physiol Biochem. 2007;143:1918-28.

78. James RABC, Zwart AB, Hare RA, Rathjen AJ, Munns R. Impact of ancestral wheat sodium exclusion genes $\mathrm{Nax} 1$ and $\mathrm{Nax} 2$ on grain yield of durum wheat on saline soils. Funct Plant Biol. 2012;39:609-18.

79. Chandra SSD, Pathak J, Kumari S, Kumar M, Poddar R, Balyan HS, Prabhu KV, Gupta PK, Mukhopadhyay K. SNP discovery from next-generation transcriptome sequencing data and their validation using KASP assay in wheat (Triticum aestivum L.). Mol Breed. 2017:37.

80. Rasheed AWW, Gao F, Zhai S, Jin H, Liu J, Guo Q, Zhang Y, Dreisigacker S, Xia X, He Z. Development and validation of KASP assays for genes underpinning key economic traits in bread wheat. Theor Appl Genet. 2016; 129:1843-60.

81. Semagn K, Babu R, Hearne S, Olsen M. Single nucleotide polymorphism genotyping using Kompetitive Allele Specific PCR (KASP): overview of the technology and its application in crop improvement. Mol Breed. 2013;33(1): $1-14$.

82. Saghai-Maroof MASK, Jorgensen RA, Allard R. Ribosomal DNA spacerlength polymorphisms in barley: Mendelian inheritance, chromosomal location, and population dynamics. Proc Natl Acad Sci U S A. 1984;81: 8014-8.

83. Purcell SNB, Todd-Brown K, Thomas L, Ferreira MAR, Bender D, Maller J. Plink: a tool set for whole-genome association and population-based linkage analyses. Am J Hum Genet. 2007;81:559-75.

84. Bradbury PJZZ, Kroon DE, Casstevens TM, Ramdoss Y, Buckler ES. TASSEL: software for association mapping of complex traits in diverse samples. Bioinformatics. 2007;23:2633-5.

85. Pritchard JKSM, Rosenberg NA, Donnelly P. Association mapping in structured populations. Am J Hum Genet. 2000;67:170-81.

86. Evanno GRSGJ. Detecting the number of clustersof individuals using the software structure: a simulation study. Mol Ecol. 2005;14:2611-20.

87. Yu JPG, Briggs WH, Bi IV, Yamasaki M, Doebley JF, McMullen MD. A unified mixed-model method for association mapping that accounts for multiple levels of relatedness. Nat Genet. 2006;28:203-8.
88. Zhang ZEE, Lai CQ, Todhunter RJ, Tiwari HK, Gore MA, Bradbury PJ. Mixed linear model approach adapted forgenome-wide association studies. Nat Genet. 2010;42:355-60.

89. Lipka AETF, Wang Q, Peiffer J, Li M, Bradbury PJ, Gore MA. GAPIT: genome association and prediction integrated tool. Bioinformatics. 2012;28:2397-9.

\section{Publisher's Note}

Springer Nature remains neutral with regard to jurisdictional claims in published maps and institutional affiliations.

\section{Ready to submit your research? Choose BMC and benefit from:}

- fast, convenient online submission

- thorough peer review by experienced researchers in your field

- rapid publication on acceptance

- support for research data, including large and complex data types

- gold Open Access which fosters wider collaboration and increased citations

- maximum visibility for your research: over $100 \mathrm{M}$ website views per year

At BMC, research is always in progress.

Learn more biomedcentral.com/submissions 